\title{
New Hybrids of ANFIS with Several Optimization Algorithms for Flood Susceptibility Modeling
}

\author{
Dieu Tien Bui ${ }^{1,2}{ }^{(0)}$, Khabat Khosravi ${ }^{3}$, Shaojun Li ${ }^{4, *}$, Himan Shahabi ${ }^{5, *}$ (D), Mahdi Panahi ${ }^{6}$ (D), \\ Vijay P. Singh ${ }^{7}$, Kamran Chapi ${ }^{8}{ }^{(1)}$, Ataollah Shirzadi ${ }^{8}$, Somayeh Panahi ${ }^{6}$, Wei Chen ${ }^{9}$ and \\ Baharin Bin Ahmad ${ }^{10}$ \\ 1 Geographic Information Science Research Group, Ton Duc Thang University, Ho Chi Minh City, Vietnam; \\ buitiendieu@tdt.edu.vn \\ 2 Faculty of Environment and Labour Safety, Ton Duc Thang University, Ho Chi Minh City, Vietnam \\ 3 Department of Watershed Management Engineering, Faculty of Natural Resources, Sari Agricultural Science \\ and Natural Resources University, Sari 48181-68984, Iran; khabat.khosravi@gmail.com \\ 4 State Key Laboratory of Geomechanics and Geotechnical Engineering, Institute of Rock and Soil Mechanics, \\ Chinese Academy of Sciences, Wuhan 430071, China \\ 5 Department of Geomorphology, Faculty of Natural Resources, University of Kurdistan, \\ Sanandaj 66177-15175, Iran \\ 6 Young Researchers and Elites Club, North Tehran Branch, Islamic Azad University, Tehran 19585-466, Iran; \\ panahi2012@yahoo.com (M.P.); somipan@yahoo.com (S.P.) \\ 7 Department of Biological and Agricultural Engineering \& Zachry Department of Civil Engineering, \\ Texas A \& M University, College Station, TX 77843-2117, USA; vsingh@tamu.edu \\ 8 Department of Rangeland and Watershed Management, Faculty of Natural Resources, \\ University of Kurdistan, Sanandaj 66177-15175, Iran; k.chapi@uok.ac.ir (K.C.); a.shirzadi@uok.ac.ir (A.S.) \\ 9 College of Geology \& Environment, Xi'an University of Science and Technology, Xi'an 710054, China; \\ chenwei.0930@163.com \\ 10 Department of Geoinformation, Faculty of Geoinformation and Real Estate, Universiti Teknologi Malaysia, \\ Skudai 81310, Malaysia; baharinahmad@utm.my \\ * Correspondence: sjli@whrsm.ac.cn (S.L.); h.shahabi@uok.ac.ir (H.S.); Tel.: +98-87-33-664-600 (H.S.)
}

Received: 6 August 2018; Accepted: 27 August 2018; Published: 7 September 2018

Abstract: This study presents three new hybrid artificial intelligence optimization models-namely, adaptive neuro-fuzzy inference system (ANFIS) with cultural (ANFIS-CA), bees (ANFIS-BA), and invasive weed optimization (ANFIS-IWO) algorithms—-for flood susceptibility mapping (FSM) in the Haraz watershed, Iran. Ten continuous and categorical flood conditioning factors were chosen based on the 201 flood locations, including topographic wetness index (TWI), river density, stream power index (SPI), curvature, distance from river, lithology, elevation, ground slope, land use, and rainfall. The step-wise weight assessment ratio analysis (SWARA) model was adopted for the assessment of relationship between flood locations and conditioning factors. The ANFIS model, based on SWARA weights, was employed for providing FSMs with three optimization models to enhance the accuracy of prediction. To evaluate the model performance and prediction capability, root-mean-square error (RMSE) and receiver operating characteristic (ROC) curve (area under the ROC (AUROC)) were used. Results showed that ANFIS-IWO with lower RMSE (0.359) had a better performance, while ANFIS-BA with higher AUROC (94.4\%) showed a better prediction capability, followed by ANFISO-IWO (0.939) and ANFIS-CA (0.921). These models can be suggested for FSM in similar climatic and physiographic areas for developing measures to mitigate flood damages and to sustainably manage floodplains.

Keywords: flood susceptibility modeling; ANFIS; cultural algorithm; bees algorithm; invasive weed optimization; Haraz watershed 


\section{Introduction}

Floods that occur in a short duration with high peak discharge [1] are considered as the worst weather-related natural hazard worldwide causing huge losses of life and property as well as deep social impacts [2-4]. Floods are more hazardous than other natural catastrophic hazards, because they affect more than 20000 lives per year and adversely impact nearly 75 million people worldwide, especially through social impacts such as homelessness, major changes in human lives, and the environment $[5,6]$. In Asia, more than $50 \%$ of economic damages as well as over $90 \%$ of all human deaths are caused due to floods $[7,8]$.

Many floods have recently occurred in Iran, especially in the northern parts, such as floods in 2012 at Noshahr, in 2013 at Neka and Behshahr, in 2013 and 2015 at Sari, and 2016 at Noshahr, which caused huge financial and human losses $[9,10]$. The frequencies and damages of these floods may increase in future due to severe climate change and extensive land-use changes in the country [11]. It is noted that a complete flood prevention is not possible; however, its spatial prediction can help mitigate its human and socio-economic losses [12]. Thus, one of the key points in flood management plans is the identification of flood prone areas so that damages can more likely be reduced by avoiding more construction and physical development in these regions. Therefore, it seems logical to seek approaches that can more and more accurately detect flood prone areas within watersheds. Flood measurement and modeling have been always considered two options for such an identification [13]. Since measurement of flood characteristics specifically during the event is hard, costly, and time consuming [14], modeling has been extensively used by scientists especially from the age of digital hydrology. A vast array modeling approaches, ranging from simple linear and empirical models to sophisticated non-linear physically-based models, have been used for flood simulations since then; however, a comprehensive and integrated flood modeling approach has not been achieved yet, due to the complexity, non-linearity, and dynamic structure of floods and their watersheds. Thus, the issue of flood occurrence forecasting and its mapping using physically-based rainfall-runoff models has remained as a challenge $[15,16]$. The weakness of one-dimensional, linear, and empirical hydrological methods is that watershed river morphology is not stable, and has dynamic characteristics, and they also take a black box view to the watershed such that they cannot provide any insight into the flooding process [17]. These models are also unable to depict rapid watershed responses [18-20]. Even though physically-based models can, to some extent, handle watershed and flood complexity, they cannot fully describe total complexity of watersheds and their hydrological phenomena [21-23]. They also require field work and a huge bulk of data as well as prohibitive computational costs and parameter estimation $[12,14,24]$. These shortcomings of classic hydrological models are required to be overcome by new approaches. Tehrany et al. [2] and Bui et al. [25] reported that in recent years, due to aforementioned drawbacks, GIS with data-driven and data mining techniques have offered new insights into natural disaster prediction which can be brought to bear on modeling multi-dimensional floods, an issue which little is known about.

A literature review reveals that all studies in the field of flood hazard modeling can be classified into two main groups including geological-geomorphological and hydrological-hydraulic methods. The first group is based on the field surveys and monitoring of evidence of overflows using remote sensing data [13]. The flood in the second group is simulated and mapped based on the peak flows for specific events or for return periods, thereby obtaining the extent of the water surface [18]. A need to huge amount of data which are not readily available in developing countries and also a need to a great deal of time for model calibration in ungagged hydrometric stations are the weaknesses of the hydrological-hydraulic methods. The generated results by geological-geomorphological methods are also more reasonable than the 1D hydrological-hydraulic methods when river channel is changeable over time and has a high erosive potential [19]. In this regard, some studies have been conducted on flood modeling using hydrological-hydraulic methods including Horritt et al. [21], Di Baldassarre et al. [22], Grimaldi et al. [23], Nguyen et al. [20], and Tyrna et al. [26]. 
However, many studies have recently been conducted to identify natural hazard prone areas around the world $[9,27-31]$ and to FSM using geological-geomorphological methods such as frequency ratio (FR) [32], weights-of-evidence (WOE) [28], logistic regression (LR) [33], analytical hierarchy process (AHP) [34], artificial neural network (ANN) [35], decision tree (DT) [36], adaptive neuro-fuzzy inference system (ANFIS) [25], ANFIS-genetic algorithm (GA) [37], bagging-LMT hybrid model and random forest [38], and ANFIS-particle swarm optimization (PSO) [39]. Application of machine learning methods in flood studies has been shown by many researchers [40]; however, no general agreement has yet been reached on the selection of the best model for any natural hazard assessment, such as flood susceptibility. Thus, new models are needed and should be tested. Tehrany et al. 2014 [28] have claimed that machine learning is the main source of methods for data driven modeling which can be applied for flooding modeling. Because floods are complex, it is difficult to model them [41], but because data mining and artificial intelligence models have a non-linear structure, they are more proper than other methods. Artificial neural networks have been widely used for natural hazard assessment among other machine learning tools because of their computational efficiency $[25,42,43]$; however, the modeling may face with errors in some cases due to their poor prediction [25]. Therefore, to bring the disadvantages of the ANN model under control; because ANFIS model high accuracy - which is a hybrid of ANN and fuzzy logic - it has been proposed by some researchers [44-47]. The ANFIS model has a better performance than the two individual models [48,49], but it has some limitations due to its weakness to find the best weight parameters which heavily influence its prediction performance [25] and it is better that these weights searched and determined by using optimization of soft computing techniques. However, there are some optimization methods that have different structures and function distributions to find the weighs of parameters. Additionally, the results of each optimization algorithm are different in each study area due to change in the geo-environmental factors. Therefore, detecting new hybrid algorithms to find the best weights and accessing the reasonable results is a crucial issue in the flood modeling process. The main differences between the current study and other studies in the field of flood susceptibility assessment is that this study uses new hybrid algorithms including ANFIS-CA, ANFIS-BA, and ANFIS-IWO for spatial prediction of floods in the Haraz watershed in the northern part of Iran. Although some optimization and machine learning algorithms have been applied for flood modeling over the world, these optimization methods have not been before explored for flood assessment.

\section{Study Area}

The Haraz watershed is one of the most flood-influenced basins in the Mazandaran province, which was selected for pilot study area. The watershed location is at the south part of Sari a capital city of Mazandaran Province, Iran (Figure 1). It lies between longitudes of $51^{\circ} 43^{\prime}$ and $52^{\circ} 36^{\prime} \mathrm{E}$, and the latitudes of $35^{\circ} 45^{\prime}$ and $36^{\circ} 22^{\prime} \mathrm{N}$, covering an area of about $4014 \mathrm{~km}^{2}$. The altitude varies from 300 to $5595 \mathrm{~m}$. The climate of the study area based on De Martonne climatic classification system is very humid and its average annual rainfall is $430 \mathrm{~mm}$. The entire study region is high land and mountainous area, for which slopes of $0-6^{\circ}$ cover only $5 \%$ and ground slope varies from $0-66^{\circ}$. Rangelands cover $92 \%$ of the study area, and — geologically—-the area is predominantly occupied by Jurassic formations. 


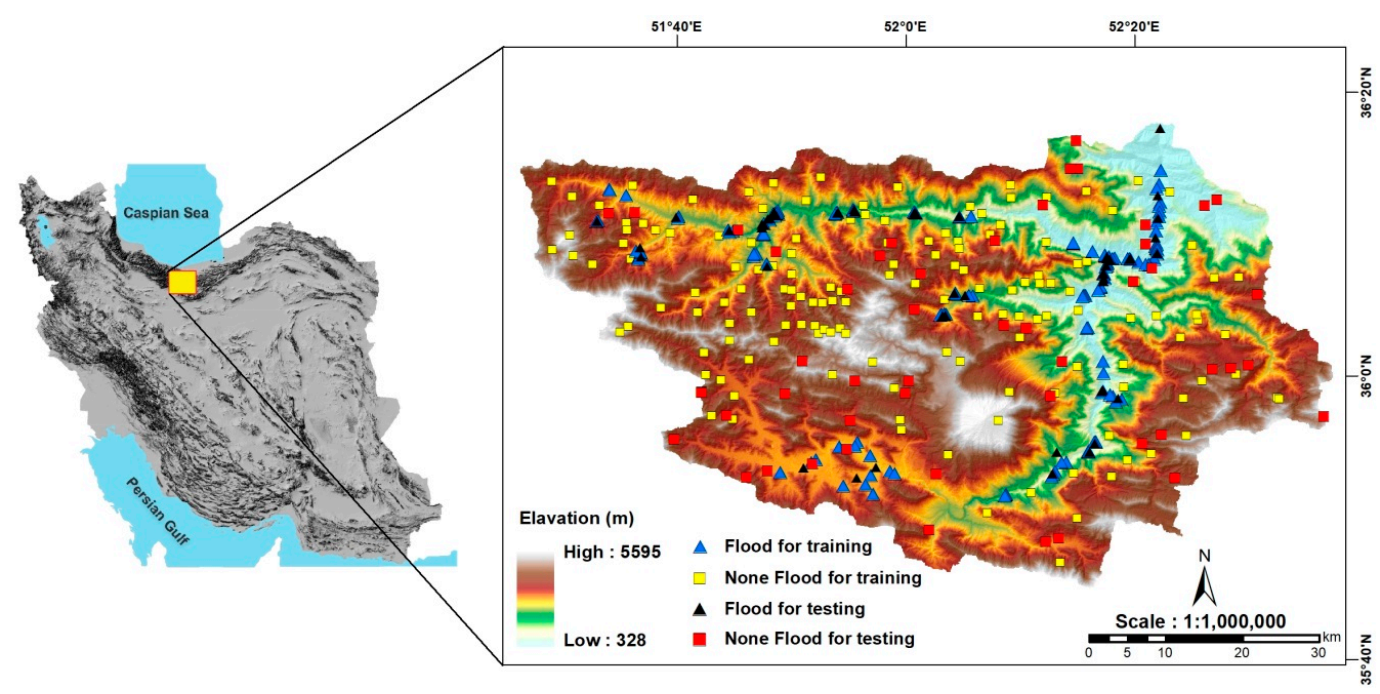

Figure 1. Flood inventory map and location of the Haraz watershed on Iran map.

\section{Data Preparation and Analysis}

The methodology of the present study is shown in Figure 2, including the following steps.

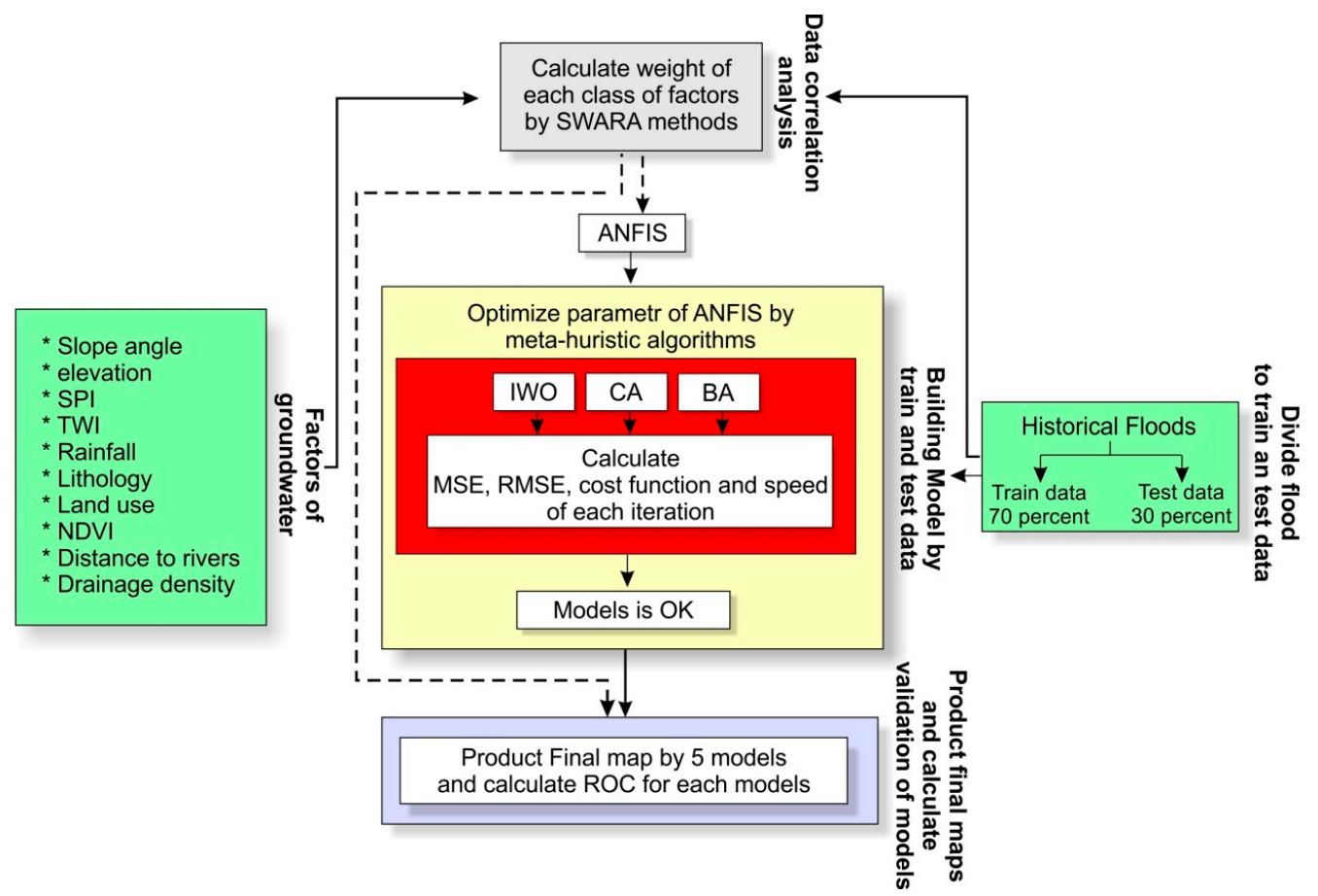

Figure 2. Methodological flowchart used in this study for FSM in the Haraz watershed.

\subsection{Flash Flood Inventory}

An inventory map is indispensable for future spatial prediction of any natural hazard assessment [50] considering single or multiple events in a specific region for recent and past events [51]. Therefore, the first step in any natural hazard susceptibility assessment is the preparation of the inventory map containing historical records [52]. In the current research, flood inventory map with 201 flood locations was generated using flood historical data from 1995 to 2015 that was finally checked during an extensive field survey. 


\subsection{Dataset Collection for Spatial Modeling}

In any natural hazard prediction, spatial relationship between hazard occurrence and conditioning factors should be analyzed [53]. In this research, 10 flood conditioning factors were based on the literature review, data availability, and characteristics of the study area, selected for flooding assessment-including ground slope, altitude, curvature, SPI, TWI, land-use, rainfall, river density, distance to river together with lithology-in a raster format with spatial resolution of $30 \mathrm{~m}$ in Environmental Systems Research Institute (ESRI) ArcGIS 10.2 [11,54].

It is very likely for one factor to have a high impact on flooding in a specific watershed while it may not show any influence in another watershed [35]. Since topographical factors are highly significant to identifying flood prone areas and also have a direct impact on the results of modeling [55], a digital elevation model (DEM) of the study area was extracted from the Advanced Spaceborne Thermal Emission and Reflection Radiometer (ASTER) Global DEM with a $30 \times 30 \mathrm{~m}$ grid size. Five geomorphic factors-such as ground slope, altitude, curvature, SPI, and TWI-were then constructed from DEM. When the ground slope increases, runoff infiltration duration decreases as well and flow velocity increases. Therefore, high volume of runoff enters the river and as result causes floods [2]. The ground slope map was constructed with eight categories [29]: $0-0.5,0.5-2,2-5,5-8,8-13,13-20,20-30$, and larger than $30^{\circ}$ (Figure 3a). According to previous studies $[9,10,29,32]$, altitude has been considered as one of the most effective factors, and since water flows from higher to lower altitudes in mountainous areas, areas of watershed located in lower altitudes have a higher potential for flood occurrence [18]. The altitude map was prepared with nine classes (Figure 3b): 328-350, 350-400, 400-450, 450-500, 500-1000, 1000-2000, 2000-3000, 3000-4000, and > $4000 \mathrm{~m}$. Flat and concave areas have a higher potential for flooding $[2,28,32]$. Curvature of the study area was constructed in three categories (Figure 3c): $<-0.1,-0.1-0.1$, and $>0.1$, namely concave, flat, and convex, respectively.

Hydrological conditioning factors, such as SPI and TWI, affect the spatial variation of flood occurrence. SPI is the erosive power of overland flow [56] and TWI is a topographic index developed by Kirkby and Beven [57] and Beven et al. [58]. TWI indicates water accumulation in a watershed. As the ground slope and catchment area increase, the amount of SPI would increase. The SPI map was constructed with nine categories (Figure 3e): 0-80, 80-400, 400-800, 800-2000, 2000-3000, and >3000 (all of them should be 1000). The TWI map was constructed with six classes (Figure 3d): 1.9-3.94, $3.95-4.47,4.48-5.03,5.04-5.71,5.72-6.96$, and 6.97-11.53.

River density and distance to river play notable roles in extend and magnitude of flood occurrence [59]. River network used to prepare river density and distance to river maps. River density was calculated by dividing the river length $(\mathrm{m})$ by the basin area $\left(\mathrm{km}^{2}\right)$ [48] and grouped into six categories, including (Figure 3e): 0-0.401, 0.401-1.17, 1.92-2.67, 2.67-3.66, and 3.66-7.3 km/ km². Field survey revealed that there are many flood occurrences adjacent to rivers, and the more the distance to river, the lower the probability of flood occurrence. The distance to river map was constructed using river and multiple ring buffer command in ArcGIS 10.2 and divided into eight classes (Figure 3h): 0-50, 50-100, 100-150, 150-200, 200-400, 400-700, 700-1000, and > $1000 \mathrm{~m}$. A lithology map of the study area with 1:100,000 scale showed six groups of formations including: Teryas, Quaternary, Permain, Cretaceous, Jurassic, and Tertiary (Figure 3i). Land-use type is considered as a conditioning factor that has a significant role in flooding [9]. The areas with higher vegetation density, such as forest regions, can control surface runoff and infiltrate the water; therefore, there is negative spatial relationship between vegetation density and flood occurrence [11]. Land-use map was generated from Landsat 8 Operational Land Imager (OLI) imagery for 2013 in Environment for Visualizing Images (ENVI) 5.1 software (The Board of Trustees of the University of Illinois, Illinois, IL, USA) and classified into seven classes—namely grassland (rangeland), bare land, forest, garden, farming land, residential, and water body—using neural network algorithm and supervised classification (Figure 3j). Rainfall is the most prominent conditioning factor for flood occurrence. About 20 years, from 1991 to 2011, meteorological data was used in order to prepare rainfall maps and then classified into six classes (Figure 3g): 183-333, 334-379, 380-409, 410-448, 449-535, and 536-741 mm using a simple kriging method. 

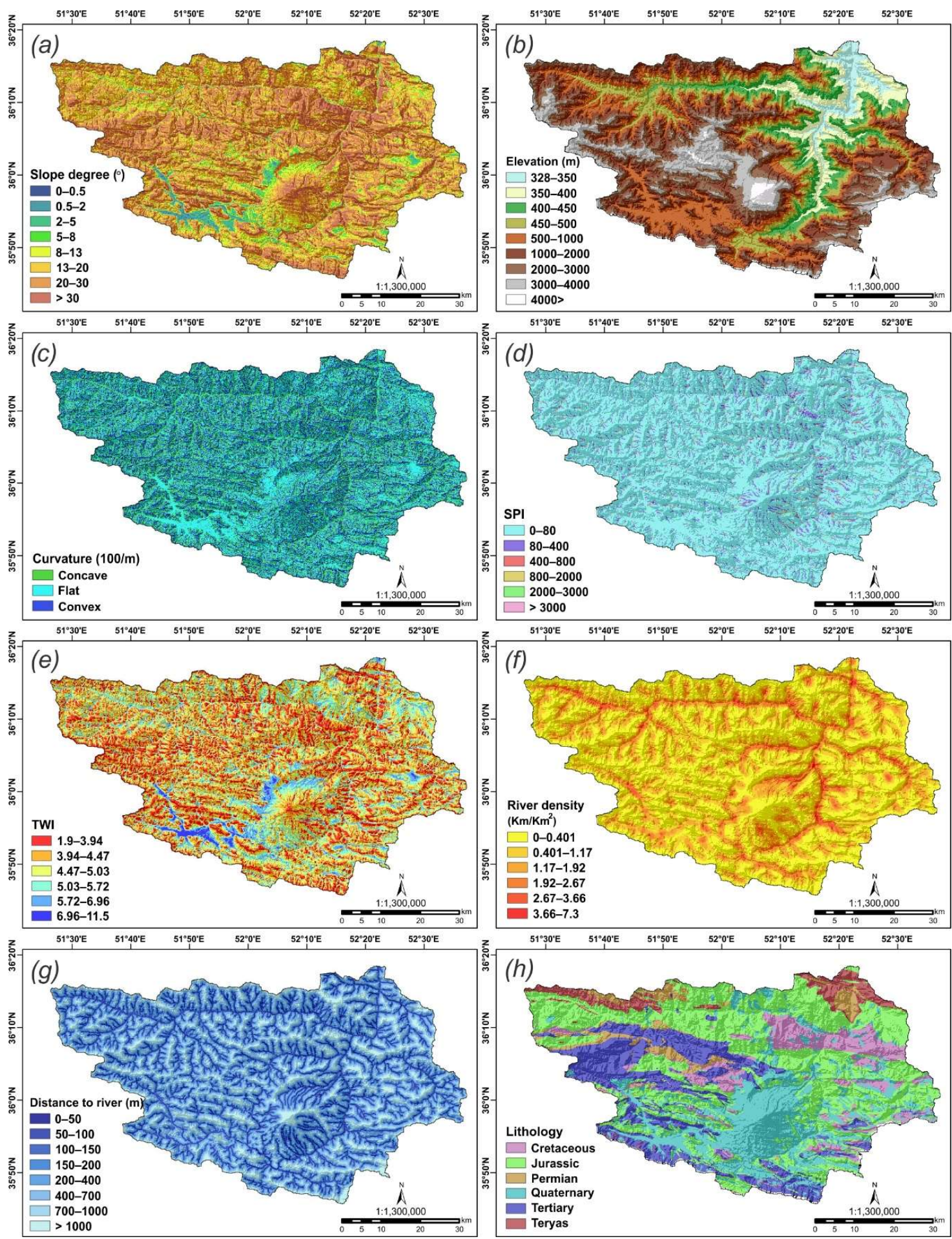

Figure 3. Cont. 


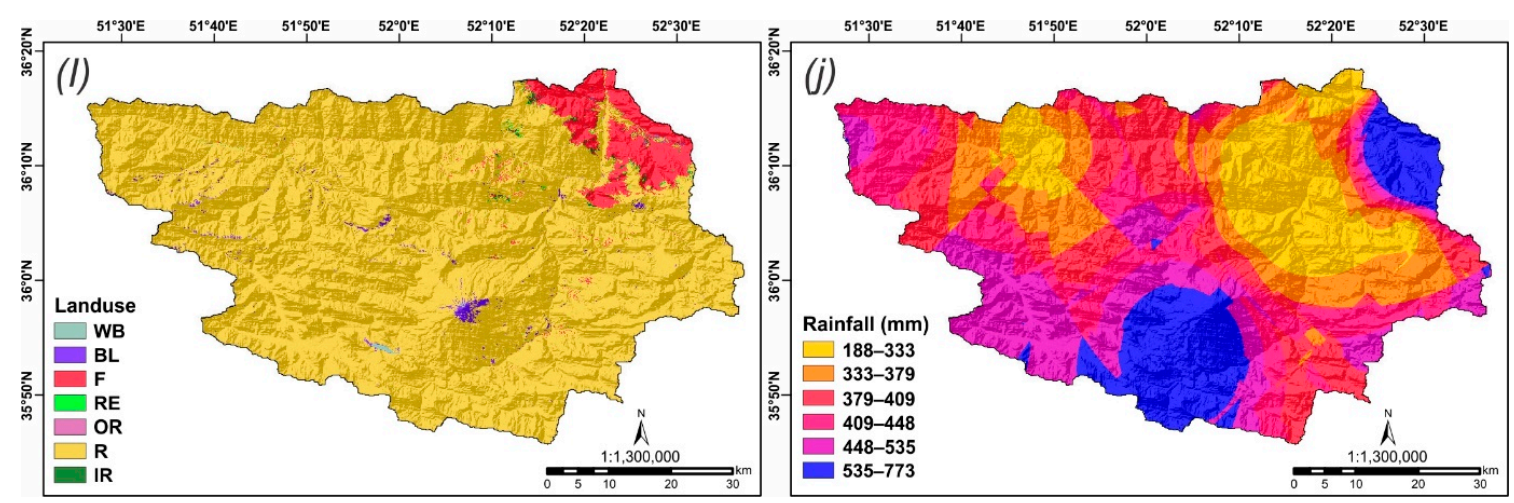

Figure 3. Flood conditioning factor maps in the study area: slope degree (a), altitude (b), curvature (c), SPI (d), TWI (e), river density (f), distance to river (g), lithology (h), land-use (i), and rainfall (j).

\subsection{Preparation of Training and Testing Dataset}

It should be noted that FSM is considered to have a binary classification in which flood index is divided into two classes, including flood or non-flood; therefore, 201 non-flood locations were first selected by Google Earth on hilly and mountainous regions that are not inundated during flood events $[9,10]$. To validate model capabilities, the inventory dataset should be divided into two groups [60], one for model construction (training dataset) and the other for model validation (testing dataset). For building the training dataset, $70 \%$ of both flood and non-flood locations were randomly selected (141 locations) and then combined together, afterwards to build the testing dataset, $30 \%$ of the remaining (60 locations) were incorporated together. Both of training and testing datasets transformed to raster format and overlaid with ten flood conditioning factors at the end. For both datasets, a value of 1 was assigned to flood pixels and a value of 0 to non-flood pixels.

\subsection{Analysis of Spatial Correlation}

SWARA method was used to display the spatial relationship between flood occurrence locations together with each conditioning factors. The SWARA method is one of the new multiple-criteria decision-making (MCDM) techniques developed in 2010 [61]. In this technique, the highest rank is apportioned to the most valuable criteria and the lowest rank is allocated to the least valuable criterion and finally, the mean values of ranks are taken into account to obtain the overall ranks [62]. The advantage of this method is that it enables the expert's opinion in relation to the accuracy of weighting to be assessed in model performance [61]. Another advantage of this method in comparison to other MCDM techniques is that experts can converse and work together, which makes for more accurate results. The SWARA method view point is different from other MCDM methods such as AHP, Analytic network process (ANP), etc. [63]; however, this method leads policy makers to make better decisions according to their goals. The Step-wise weight assessment ratio analysis (SWARA) method was used only for determining the initial weights as input for modeling. In this study, we invited some hydrology experts to prioritize and rank the order of sub-classes of each conditioning factor.

According to Keršuliene et al. [61], the importance relativity of the mean value, $S_{j}$ was determined by

$$
\mathrm{S}_{\mathrm{j}}=\frac{\sum_{\mathrm{i}}^{\mathrm{n}} \mathrm{A}_{\mathrm{i}}}{\mathrm{n}}
$$

where $\mathrm{n}$ stands for the number of experts, $\mathrm{i}$ is counter in sigma, $\mathrm{A}_{\mathrm{i}}$ shows the offered ranks by the experts for each factor, and $\mathrm{j}$ represents the number of the factor.

Afterwards, the coefficient $K_{j}$ is determined by

$$
K_{j}= \begin{cases}1 & j=1 \\ S_{j}+1 & j>1\end{cases}
$$


The recalculated weight $Q_{j}$ is calculated as

$$
\mathrm{Q}_{\mathrm{j}}=\frac{\mathrm{Q}_{\mathrm{j}-1}}{\mathrm{~K}_{\mathrm{j}}}
$$

The comparative weights of evaluation criteria are verbalized as

$$
W_{j}=\frac{Q_{j}}{\sum_{j=1}^{m} Q_{j}}
$$

where $W_{j}$ presents the relative weight of the jth criterion, and $m$ shows the total number of criteria.

\subsection{Flood Spatial Prediction Modeling}

In the present study, three new ensemble models-ANFIS-CA, ANFIS-BA, and ANFIS-IWO-were selected to determine the most susceptible flood areas as well as their comparison.

\subsubsection{Adaptive Neuro-Fuzzy Inference System}

Takagi and Sugeno [64] presented ANFIS that was obtained from ANN and fuzzy logic [65] by catching the advantages of both in one framework. The ANN's learning capability is automatic. However, this model cannot describe how it acquires the output from decision making. On the contrary, the fuzzy logic can produce output out of fuzzy logic decision, but it does not have the ability to automate learnings [66]. An ANFIS, derived from nature, generates input and output data pairs, so it has been successfully used in diverse fields at solving nonlinear issues and indicating problems [67]. The architecture of ANFIS training is shown in Figure 4. The ANFIS is a feed forward neural network with multi-layer structure. In general, the layers of ANFIS are constructed from six layers with the following function:

Layer 1 (input layer): Layer 1 is the layer of input with the amount of $x$ and $y$ passed to the number of neurons in the next layer.

Layer 2 (fuzzification layer): Every node i in Layer 2, also called the 'fuzzification layer', consists of an adaptive node (square node) which has a node function $A_{i}$ or $B_{i-2}$ as the linguistic label related to the input node i. Therefore, in Layer 2, fuzzy membership function, is computed which determines 'full', 'partial', or 'none' membership levels. The output function is calculated according to the equations

$$
\begin{gathered}
\mathrm{Q}_{1, \mathrm{i}}=\mu_{\mathrm{A}_{\mathrm{i}}}\left(\mathrm{x}_{1}\right) \quad \text { for } \mathrm{i}=1,2 \\
\mathrm{Q}_{1, \mathrm{i}}=\mu_{\mathrm{B}_{\mathrm{i}-2}}\left(\mathrm{x}_{2}\right) \text { for } \mathrm{i}=1,2
\end{gathered}
$$

Several membership functions for fuzzifying used many research such as triangular, trapezoidal, Gaussian, and Bell functions. In this research, we used the Bell function such that $\mu_{\mathrm{A}_{\mathrm{i}}}\left(\mathrm{x}_{1}\right)$ is given by

$$
\mu_{A_{i}}\left(x_{1}\right)=\frac{1}{1+\left(\frac{x-c_{i}}{a_{i}}\right)^{2 b_{i}}}
$$

where $a_{i}, b_{i}$, and $c_{i}$ are the parameters of the Bell function that are so-called premise parameters $[65,68]$.

Layer 3 (antecedent layer): All nodes in this layer are fixed nodes labeled as $\Pi$. In this layer, the aim is to calculate the firing strength for each rule, called $\mathrm{w}_{\mathrm{i}}$ and the following equation computes the outputs

$$
\mathrm{Q}_{2, \mathrm{i}}=\mathrm{w}_{\mathrm{i}}=\mu_{\mathrm{A}_{\mathrm{i}}}(\mathrm{x}) \cdot \mu_{\mathrm{B}_{\mathrm{i}}}(\mathrm{y}) \quad \text { for } \mathrm{i}=1,2
$$

Layer 4 (strength normalization layer): All nodes in this layer are fixed nodes (square nodes) labeled N. Each node calculates the individual rules firing strength ratio to the total number of all 
rules firing strengths. Output is called the normalized firing strength, determined for each node by the equation

$$
\mathrm{Q}_{3, \mathrm{i}}=\frac{\mathrm{w}_{\mathrm{i}}}{\sum \mathrm{w}_{\mathrm{i}}}=\frac{\mathrm{w}_{\mathrm{i}}}{\mathrm{w}_{1}+\mathrm{w}_{2}}=\mathrm{w}_{\mathrm{i}} \quad \text { for } \mathrm{i}=1,2
$$

Layer 5 (consequent layer): This layer is the adaptive layer for every node which is known as the defuzzification layer. Every node is an adaptive square node with the node function. It can be defined as

$$
\mathrm{Q}_{4,1}=\mathrm{w}_{\mathrm{i}} \cdot \mathrm{f}_{\mathrm{i}}=\mathrm{w}_{\mathrm{i}} \cdot\left(\mathrm{p}_{\mathrm{i}} \mathrm{x}+\mathrm{q}_{\mathrm{i}} \mathrm{y}+\mathrm{r}_{\mathrm{i}}\right) \quad \text { for } \mathrm{i}=1,2
$$

where $\mathrm{p}_{\mathrm{i}}, \mathrm{q}_{\mathrm{i}}$, and $\mathrm{r}_{\mathrm{i}}$ are the consequent parameters of function fuzzy inference system $\left(\mathrm{f}_{\mathrm{i}}\right)$.

Layer 6 (inference layer): This layer is a single node which calculates the total number of all received signals from the defuzzification layer in order to generate the overall output shown by circle and labeled $\sum$ and $\mathrm{f}_{\text {out }}$ is final output. It can be described as

$$
\mathrm{Q}_{5,1}=\sum \mathrm{w}_{\mathrm{i}} \cdot \mathrm{f}_{\mathrm{i}}=\frac{\sum \mathrm{w}_{\mathrm{i}} \cdot \mathrm{f}_{\mathrm{i}}}{\sum \mathrm{w}_{\mathrm{i}}}=\mathrm{f}_{\text {out }}
$$

Several researches have recently optimized the parameters of fuzzy membership in ANFIS by using metaheuristic algorithms which has improved the results $[69,70]$. In this study, cultural algorithms (CA), bees algorithm (BA), and invasive weed optimization algorithm (IWO) were used for optimizing premise parameters of bell function.

(a)

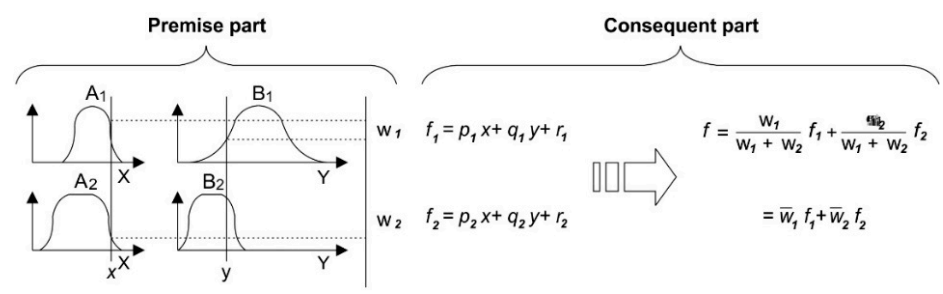

(b)

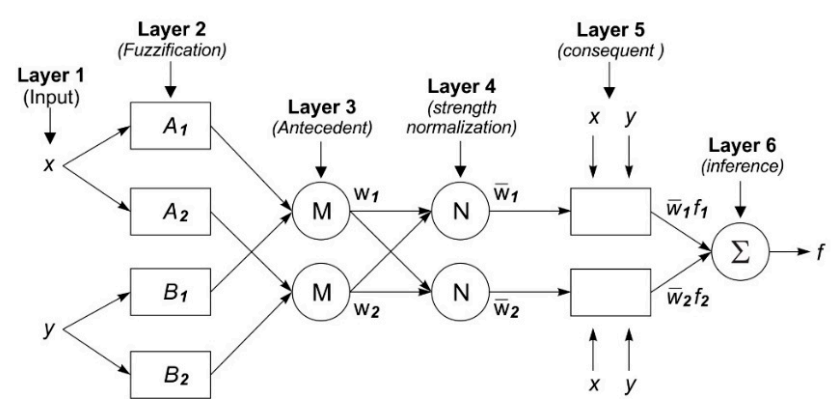

Figure 4. General ANFIS architecture of first order Takagi-Sugeno fuzzy model [65]: (a) Multi-layer perception fuzzy reasoning; (b) equivalent ANFIS structure.

Hybrid models can find the relationships between the SWARA values of each conditioning factor through training dataset. In the modeling process, the optimization algorithms have been performed in three steps (Figure 5) including (i) dividing dataset into two datasets in a 70/30\% ratio for model building (training dataset) and model validation (testing dataset), respectively; (ii) construction of bell function in an ANFIS as a membership function and determination of the clusters were performed. Each cluster follows the bell function, that each function parameter of bell function has been optimized by cultural algorithm (CA), bees algorithm (BA), invasive weed optimization algorithm (IWO). We defined the cost function (RSME) and utilize training dataset for optimizing parameters of the bell function of ANFIS; iii) the prediction power of each model has been calculated by the testing dataset. 


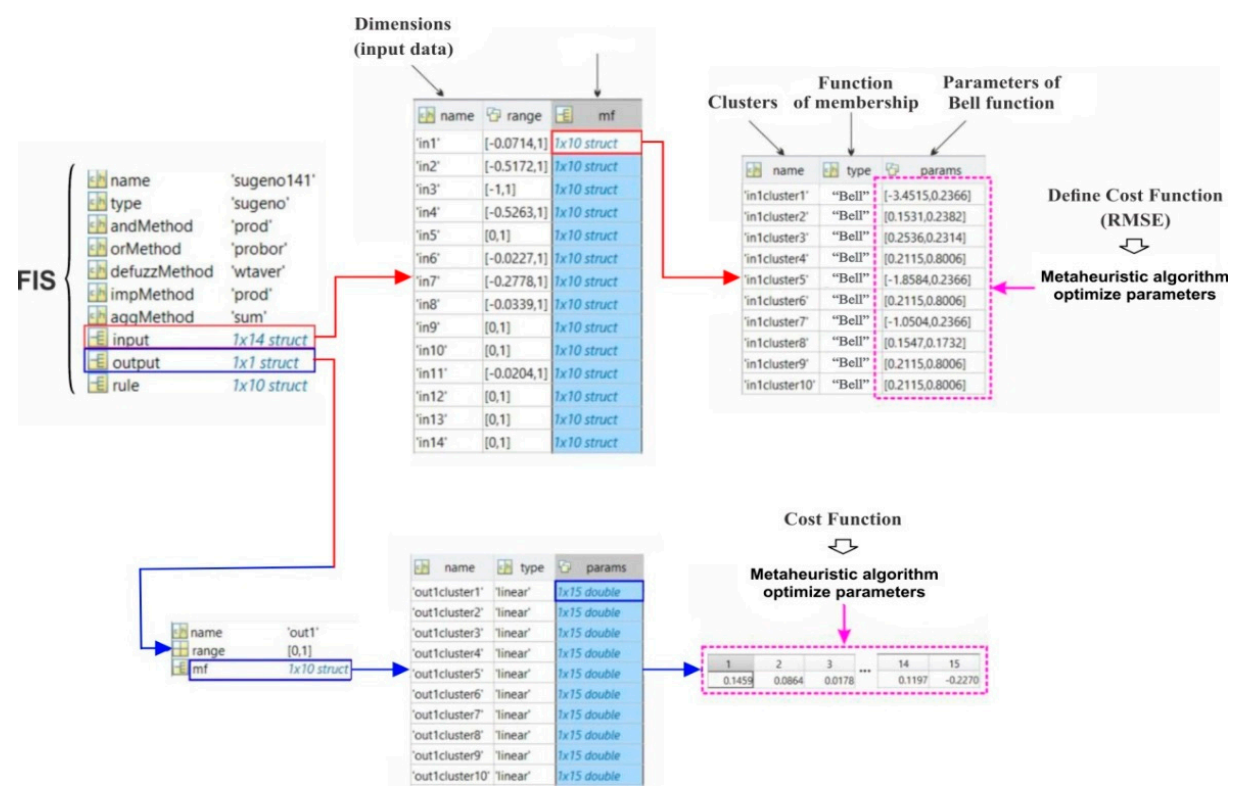

Figure 5. Flowchart of modelling process in this study.

\subsubsection{Cultural Algorithm}

Cultural algorithm (CA) is an evolutionary algorithm introduced by Reynolds [71]. CA expresses an ideal framework of various theories of social evolution with the concept of collective intelligence developed in the 19th century. CA is a computational model of cultural evolution in solving optimization problems that need a vast amount of domain knowledge to steer the collective decisions of individuals in the population. CA has been applied to problems by extensive data, numerous domain limitations, many objectives, and multiple agents in a vast distributed social network. Concluded from social structures, CA compounds evolutionary systems and agents using multiple knowledge sources for the evolution process. Cultural algorithms include two major parts: the space of population and the atmosphere of belief [72]. These two spaces are connected via a communication protocol describing how to link both spaces with the rules for people who believe in their own experiences. These interactions are shown in Figure 6. The population space can include any population-based computational models, like genetic algorithms and evolutionary programming [73]. The belief space supports the information reservoir which every one of their experiences is for other individuals to learn them indirectly.

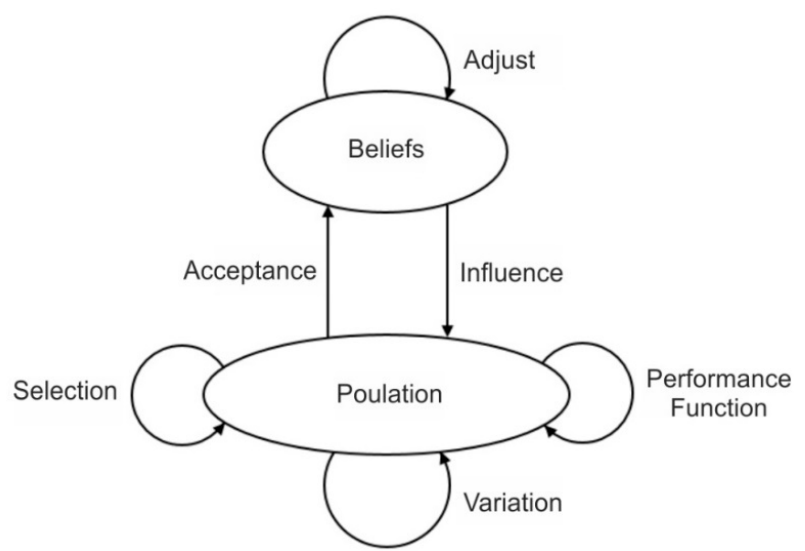

Figure 6. Spaces of a cultural algorithm [74]. 


\subsubsection{Bees Algorithm}

Another heuristic algorithm is the bees algorithm, which is bee swarm-based. Originally, this algorithm introduced by Pham et al. [75], which is inspired by the foraging behavior of a group of bees when they try to find food resources around their hives [75]. First, the scout bees are distributed uniformly and randomly in different directions to be able to find flower patches in each spot. After identifying the flower patches, the scout bees go back to the hive and start a special dance which is known as the 'waggle dance' and it is used for communicating with other group members to share information regarding the flower patches they have already identified. This information may include the direction, the distance to the hive, as well as the amount of nectar existing in the flower patches. The accumulated information shared by these scout bees helps the hive or, in other words, the colony, have a proper assessment of all flower patches available. After accomplishing this phase, the scout bees escort another kind of bees known as the 'recruit bees' to go to the discovered flower patches. Different quantities of recruit bees are assigned to each scout bee based on the distance of flower patches as well as the amount of available nectar. In other words, if one flower patch has a higher quality than another one, more recruit bees follow them. Afterwards, the recruit bees constantly assess the flower patch quality while doing the harvest process until the flower patch quality declines. Then, they will leave the flower patch immediately. However, if patch has a steady and satisfactory quality, it will be announced via another waggle dance.

Figure 7 shows the flowchart for bee algorithm. First of all, to implement this algorithm, n numbers of bees are uniformly distributed in a random manner throughout the search space. The algorithm then starts assessing the fitness for each determined site by the scout bees until the most prope-or optimized-bee is chosen as the 'elite bee'. The sites of these bees are selected form vicinity of searches' area and the algorithm explores in the selected sites bees in order to find the best bees at the time when numbers of bees are at its high level. For each site, only the most appropriate bee is being chosen to survive for the next generation. The remaining bees are randomly assigned around the scouting area for new potential solutions. The phase continues so long as the algorithm reaches convergence.

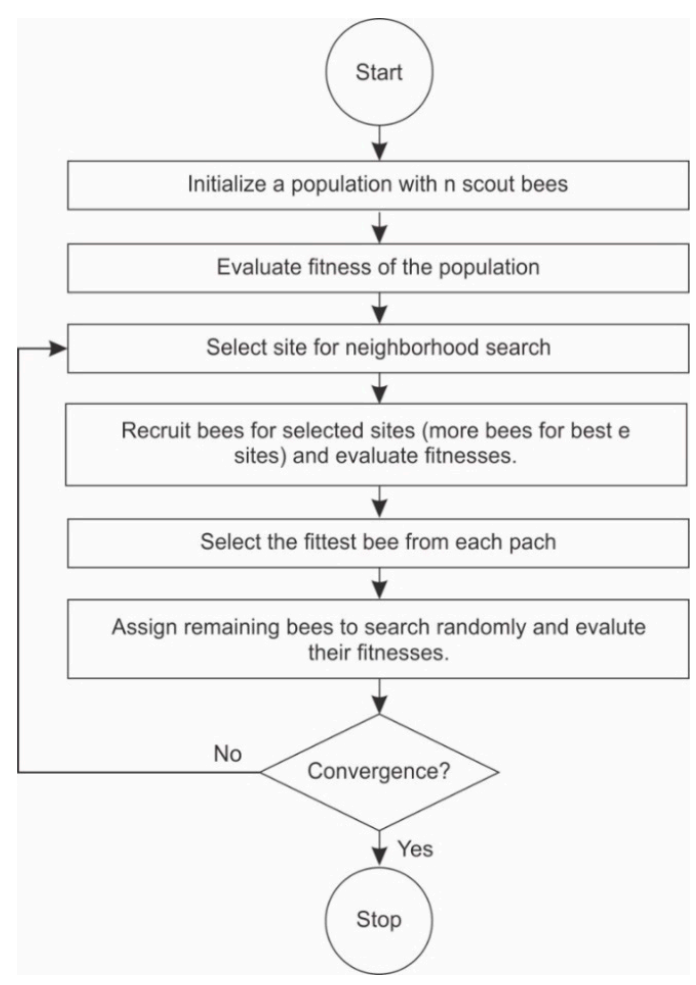

Figure 7. Flowchart of the BA for flood susceptibility mapping in Haraz watershed [76]. 


\subsubsection{Invasive Weed Optimization Algorithm}

Based on the method which originally developed by Mehrabian and Lucas [77] to optimize growth's place of weeds and their reproduction, IWO algorithm is another meta-heuristic algorithm which has been used to imitate the colonizing weeds' behavior. Among the specifications of this algorithm, its simple form, few input parameters, strong robustness, as well as ease of understanding have made it popular for application in problematic nonlinear optimization [78-80]. Furthermore, the IWO algorithm has more optimized solutions for problems in comparison with other algorithms such as particle swarm optimization (PSO) and shuffled frog leaping algorithm (SFLA) and in some cases even it has a better performance than the stated algorithms [78]. The IWO algorithm has five components as follows:

(1) Initialization

It involves a random distribution of restricted weeds in the searching space with $\mathrm{d}$ dimension that it is number of factors of flood, which in fact is the earliest population of solutions.

(2) Reproduction

During the growing period, weeds are allowed to reproduce a specific number of seeds according to their fitness. As a matter of fact, numbers of reproduced seeds or their $S_{\min }$ starts from worth fitness and increases to reach $S_{\max }$ for the weeds with the best fitness, as shown in Figure 8.

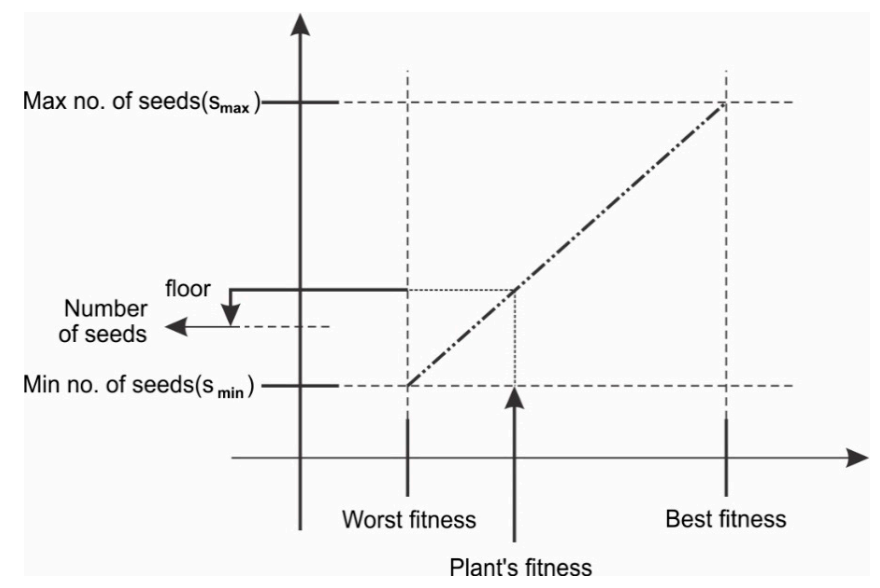

Figure 8. Procedure of seed reproduction at weeds' colony [77].

(3) Spatial Dispersal

Reproduced seeds are being distributed by chance all over the searching region. So that they can be located close to their family with the average value which is equal to zero and has non-identical variances. Additionally, in every iteration, the standard deviation (SD) decreases from $\sigma_{\min }$ to $\sigma_{\max }$ and is calculated with via non-linear equation which is

$$
\sigma_{\text {iter }}=\frac{\left(\text { iter }_{\max }-\text { iter }^{\mathrm{n}}\right.}{\left(\text { iter }_{\max }\right)^{\mathrm{n}}}\left(\sigma_{\min }-\sigma_{\max }\right)+\sigma_{\max }
$$

where iter max $_{\text {is }}$ is the number of last iteration, $\sigma_{\text {iter }}$ is the corresponding iteration's SD, $\mathrm{n}$ is the nonlinear modulation index between 2 and $3, \sigma_{\max }$ is maximum value's SD and $\sigma_{\min }$ is minimum value's SD [81].

(4) Competitive Exclusion

All weeds together with their seeds are combined to create the population for the next generation. If the population surpasses a definite maximum, the weeds with less fitness will be eradicated. 
Reproduction and competition pave the way for the reproduction of the fittest weeds. Therefore, if they produce fitter seeds, seeds can remain alive in the competition.

(5) Termination Condition

Steps 2 to 4 are repeated when the iteration reaches to the maximum defined amount and weeds have the maximum fitness that are closest to optimal solution.

\subsubsection{Performance Assessment}

Quantitative approaches to determine the accuracy of the models are different between observed and estimated values, defined as a forecasting error. In the current study, the capability of models for flood prediction was evaluated using a statistical criterion namely root-mean-squared error (RMSE) as

$$
\text { RMSE }=\sqrt{\frac{\sum_{\mathrm{i}=1}^{\mathrm{n}}\left(\mathrm{O}_{\mathrm{i}}-\mathrm{E}_{\mathrm{i}}\right)^{2}}{\mathrm{~N}}}
$$

where $\mathrm{O}_{\mathrm{i}}$ and $\mathrm{E}_{\mathrm{i}}$ are observation and prediction of flood probability values, respectively, in training and testing datasets, and $\mathrm{N}$ is all samples.

\subsection{Model Validation and Comparisons}

All in all, forecasting capability of flood spatial modeling was analyzed for training and testing datasets [11] using ROC and AUROC, as a standard useful technique to evaluate the prediction capability of models [82,83], the ROC curve is a graph with specificity on the x-axis and sensitivity on the y-axis. Specificity is the number of incorrectly classified floods per total predicted non-floods while sensitivity is the number of correctly classified floods per total predicted floods [84]. The higher the AUROC value is, the better the prediction capability of models will be better [85]. The AUROC can be formulated as

$$
\mathrm{AUROC}=\frac{\sum \mathrm{TP}+\sum \mathrm{TN}}{\mathrm{P}+\mathrm{N}}
$$

where TP and TN are the number of floods that correctly classified as floods and non-floods, respectively. $\mathrm{P}$ and $\mathrm{N}$ are the number of total pixels which defines as floods and non-floods, respectively [38]. Results of model performance on training data (success rate) shows a degree of fit of a flood model with the training dataset, indicating how suitable the built model is for flood susceptibility evaluation; therefore, this is not an appropriate method to show the capability of model prediction $[51,86,87]$. Performance of model using testing/validating dataset (prediction rate) shows how good a model is; thus, this approach should be used for evaluation of model prediction capability. In this research, both success and prediction rates were performed using the training and testing datasets with flood susceptibility index.

\subsection{Inferential Statistics}

\subsubsection{Freidman Test}

In the present research, a non-parametric test-namely the Freidman [88] test which is one of the most credible tests for multiple comparisons [89]—-was used to find significant differences between models. This test has ranking for each row by considering the rank values of each columns. The null hypothesis $\left(\mathrm{H}_{0}\right)$ for the current research shows that there is no difference between prediction capabilities of flood models. If the amount of the p-value (significance) is smaller than the significance level $(\alpha=0.05)$, then the null hypothesis is rejected. The biggest weakness of this technique is that it only shows whether there is difference among the models performance or not, and it does not have any capability to display pairwise comparisons among the models. 


\subsubsection{Wilcoxon Test}

To overcome Freidman's test weakness, another non-parametric test-Wilcoxon test-was used. This test is used when the aim is to compare two related samples, matched samples, or paired data. The Wilcoxon test prepares pairwise comparisons between all performed flood susceptibility models. The null hypothesis for Wilcoxon test is similar to Friedman's test. The p-value and z-score were applied to assess the differences between flood susceptibility models.

\section{Results}

\subsection{Spatial Relationship between Flood Occurrence and Conditioning Factors}

The spatial correlations between flood occurrence and conditioning factors were evaluated, as shown in Table 1. The highest value of SWARA belonged to the first class of 0-0.5 (0.4); therefore, the steeper the ground slope, the lower the flood occurrence probability. The SWARA values decrease when elevation increases and the lowest elevation of 328-350 $\mathrm{m}$ had the highest impact (0.63) on the flood occurrence. Generally, the lowest and highest elevations had the highest and lowest influences on flood occurrence, respectively. In the case of curvature, the concave landscape had the highest influence on flooding (0.46), followed by flat (0.43) and then convex (0.11). For SPI, the highest value belonged to class of 2000-3000 (0.32) and values decreased by SPI reducing. The TWI value had a direct impact on flood occurrences events; the greater the TWI, the higher the flood occurrence probability. For the present study, the highest (0.08) and lowest (0) SWARA values belonged to the highest (6.9-11.5) and lowest (1.9-3.9) TWI values. For river density, the class of 2.67-3.66 and 3.66-7.3 showed the highest probability (0.37) and the class of $0-0.4$ had the lowest probability (0) of flooding. Results revealed that the more the river density, the higher the flooding probability. The SWARA values showed a decreasing trend when the distance to rivers increased, as the highest and lowest SWARA values belonged to the distance of $0-50 \mathrm{~m}(0.59)$ and more than $700 \mathrm{~m}(0)$, respectively. According to $[2,9,10,28]$, the most prone areas to flood occurrence were the areas with the lowest elevation, lowest ground slope, flat area, and that were closest to rivers. In the case of lithology, Teryas formations had the highest impact on flooding (0.31), followed by Quaternary (0.21), Permain (0.21), Cretaceous (0.15), Jurassic (0.07), and Tertiary (0.06) formations. Results showed that the land use of water bodies had the highest influence on flooding (0.75), followed by residential area (0.15), garden (0.06), forestlands (0.02), grasslands (0.01), farmlands (0), and barren lands (0). The lowest amount of rainfall (188-333 $\mathrm{mm}$ ) had the highest impact (0.4) on flooding. In the study area, the more the rainfall, the lower the flooding probability, due to the fact that-in mountainous areas-rainfall would increase with elevation increase; however, flooding occurs at lower elevations.

Table 1. Spatial relationship between flood-conditioning factors and flooding occurrences locations by SWARA method

\begin{tabular}{|c|c|c|c|c|c|}
\hline Sub-Factor & Class & $\begin{array}{c}\text { Comparative } \\
\text { Importance of } K_{j} \\
\text { Average Value }\end{array}$ & $\begin{array}{l}\text { Coefficient } \\
K_{j}=S_{j}+1\end{array}$ & $\left.\mathrm{w}_{\mathrm{j}}=(\mathrm{Qj}-1)\right) / \mathrm{k}_{\mathrm{j}}$ & Weight $\mathbf{w}_{\mathbf{j}} / \Sigma \mathbf{w}_{\mathbf{j}}$ \\
\hline \multirow[t]{8}{*}{ Slope } & $0-0.5$ & & 1.00 & 1.00 & 0.40 \\
\hline & $0.5-2$ & 0.80 & 1.80 & 0.56 & 0.22 \\
\hline & $2-5$ & 0.20 & 1.20 & 0.46 & 0.18 \\
\hline & $5-8$ & 0.60 & 1.60 & 0.29 & 0.11 \\
\hline & $8-13$ & 1.15 & 2.15 & 0.13 & 0.05 \\
\hline & $13-20$ & 1.50 & 2.50 & 0.05 & 0.02 \\
\hline & $20-30$ & 0.55 & 1.55 & 0.01 & 0.00 \\
\hline & $>30$ & 2.70 & 3.70 & 0.01 & 0.01 \\
\hline \multirow[t]{4}{*}{ Elevation } & $328-350$ & & 1.00 & 1.00 & 0.63 \\
\hline & $350-400$ & 0.35 & 1.35 & 0.16 & 0.10 \\
\hline & $400-450$ & 3.70 & 4.70 & 0.21 & 0.13 \\
\hline & $450-500$ & 0.55 & 1.55 & 0.10 & 0.06 \\
\hline
\end{tabular}


Table 1. Cont.

\begin{tabular}{|c|c|c|c|c|c|}
\hline Sub-Factor & Class & $\begin{array}{l}\text { Comparative } \\
\text { Importance of } K_{j} \\
\text { Average Value }\end{array}$ & $\begin{array}{l}\text { Coefficient } \\
K_{j}=S_{j}+1\end{array}$ & $\left.w_{j}=(Q j-1)\right) / k_{j}$ & Weight $w_{j} / \Sigma w_{j}$ \\
\hline & $500-1000$ & 0.65 & 1.65 & 0.06 & 0.04 \\
\hline & 1000-2000 & 3.95 & 4.95 & 0.01 & 0.01 \\
\hline & $2000-3000$ & 0.00 & 1.00 & 0.01 & 0.01 \\
\hline & $3000-4000$ & 0.00 & 1.00 & 0.01 & 0.01 \\
\hline & $>4000$ & 0.00 & 1.00 & 0.01 & 0.01 \\
\hline \multirow[t]{3}{*}{ Curvature } & Concave & & 1.00 & 1.00 & 0.46 \\
\hline & Flat & 0.05 & 1.05 & 0.95 & 0.43 \\
\hline & Convex & 3.00 & 4.00 & 0.24 & 0.11 \\
\hline \multirow{6}{*}{ SPI } & $0-80$ & 3.70 & 4.70 & 0.09 & 0.03 \\
\hline & $80-400$ & 0.70 & 1.70 & 0.41 & 0.13 \\
\hline & $400-800$ & 0.30 & 1.30 & 0.70 & 0.22 \\
\hline & $800-2000$ & 0.10 & 1.10 & 0.91 & 0.29 \\
\hline & $2000-3000$ & & 1.00 & 1.00 & 0.32 \\
\hline & $>3000$ & 3.95 & 4.95 & 0.02 & 0.01 \\
\hline \multirow[t]{6}{*}{ TWI } & $1.9-3.94$ & 0.05 & 1.05 & 0.03 & 0.00 \\
\hline & $3.94-4.47$ & 3.50 & 4.50 & 0.03 & 0.00 \\
\hline & $4.47-5.03$ & 2.70 & 3.70 & 0.15 & 0.01 \\
\hline & $5.03-5.72$ & 0.65 & 1.65 & 0.55 & 0.04 \\
\hline & $5.72-6.96$ & 0.10 & 1.10 & 0.91 & 0.07 \\
\hline & $6.96-11.5$ & & 1.00 & 1.00 & 0.08 \\
\hline \multirow[t]{6}{*}{ River density } & $0-0.401$ & 3.95 & 4.95 & 0.01 & 0.00 \\
\hline & $0.401-1.17$ & 3.95 & 4.95 & 0.03 & 0.01 \\
\hline & $1.17-1.92$ & 2.50 & 3.50 & 0.15 & 0.06 \\
\hline & $1.92-2.67$ & 0.85 & 1.85 & 0.54 & 0.20 \\
\hline & $2.67-3.66$ & & 1.00 & 1.00 & 0.37 \\
\hline & $3.66-7.3$ & 0.00 & 1.00 & 1.00 & 0.37 \\
\hline \multirow[t]{8}{*}{ Distance to river } & $0-50$ & & 1.00 & 1.00 & 0.59 \\
\hline & $50-100$ & 1.75 & 2.75 & 0.36 & 0.22 \\
\hline & 100-150 & 0.85 & 1.85 & 0.20 & 0.12 \\
\hline & 150-200 & 1.20 & 2.20 & 0.09 & 0.05 \\
\hline & $200-400$ & 2.70 & 3.70 & 0.02 & 0.01 \\
\hline & $400-700$ & 2.70 & 3.70 & 0.01 & 0.00 \\
\hline & $700-1000$ & 3.00 & 4.00 & 0.00 & 0.00 \\
\hline & $>1000$ & 0.00 & 1.00 & 0.00 & 0.00 \\
\hline \multirow[t]{6}{*}{ Lithology } & Teryas & & 1.00 & 1.00 & 0.31 \\
\hline & Quaternary & 0.50 & 1.50 & 0.67 & 0.21 \\
\hline & Permain & 0.00 & 1.00 & 0.67 & 0.21 \\
\hline & Cretaceous & 0.40 & 1.40 & 0.48 & 0.15 \\
\hline & Jurassic & 1.10 & 2.10 & 0.23 & 0.07 \\
\hline & Teratiary & 0.10 & 1.10 & 0.21 & 0.06 \\
\hline \multirow[t]{7}{*}{ Land use } & Water bodies & & 1.00 & 1.00 & 0.75 \\
\hline & Residential area & 3.90 & 4.90 & 0.20 & 0.15 \\
\hline & Garden & 1.55 & 2.55 & 0.08 & 0.06 \\
\hline & Forest land & 2.00 & 3.00 & 0.03 & 0.02 \\
\hline & Grassland & 0.70 & 1.70 & 0.02 & 0.01 \\
\hline & Farming land & 3.95 & 4.95 & 0.00 & 0.00 \\
\hline & Barren land & 0.00 & 1.00 & 0.00 & 0.00 \\
\hline \multirow[t]{6}{*}{ Rainfall } & $188-333$ & & 1.00 & 1.00 & 0.40 \\
\hline & $333-379$ & 0.10 & 1.10 & 0.31 & 0.12 \\
\hline & 379-409 & 1.20 & 2.20 & 0.45 & 0.18 \\
\hline & $409-448$ & 0.35 & 1.35 & 0.34 & 0.13 \\
\hline & $448-535$ & 0.05 & 1.05 & 0.29 & 0.12 \\
\hline & $535-471$ & 1.15 & 2.15 & 0.14 & 0.05 \\
\hline
\end{tabular}

\subsection{Model Comparison between the Proposed New ANFIS Ensemble Models}

The newly designed three ANFIS ensemble optimization models-namely ANFIS-CA, ANFIS-BA, and ANFIS-IWO-were used with MATLAB R2016 and ArcGIS 10.2. These models were trained, like other smart models, based on a part of data. Therefore, all data of flood and non-flood points were divided into two categories with the ratio of 30 and 70 percent used as training and test data, respectively. 
Training and testing datasets were used as fundamental elements of these models. The training dataset for these three hybrid models was applied to find the relationship between SWARA and values of flood (1) and non-flood (0) locations and finally using testing data, the accuracy of the built model was investigated. Accuracy of training and testing is shown in Figure 9a-f. According to Figure 9a,c,e, the RMSE for ANFIS-CA, ANFIS-BA, and ANFIS-IWO in the training was 0.314, 0.274, and 0.067, respectively. Thus, the hybrid model of ANFIS-IWO showed a better performance with training dataset and had a higher degree of fit; however, the best optimized model was the one which predicted the results of the test data with a higher accuracy. The values of RMSE for testing datasets are shown in Figure $9 \mathrm{~b}, \mathrm{~d}, \mathrm{f}$. The values of RMSE for ANFIS-CA, ANFIS-BA, and ANFIS-IWO in testing process were $0.449,0.365$, and 0.359 , respectively. Therefore, the ANFIS-IWO optimization algorithm indicated a better performance for both training and testing phases, followed by ANFIS-BA and ANFIS-CA.
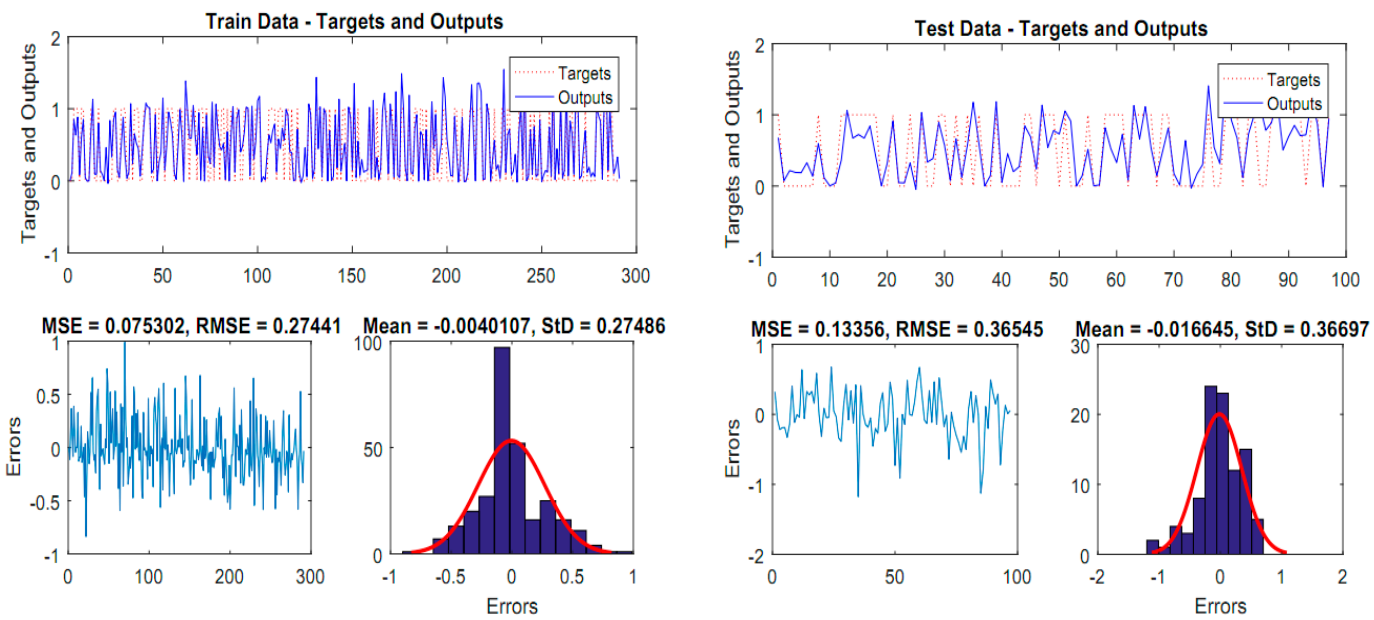

(a)

(b)
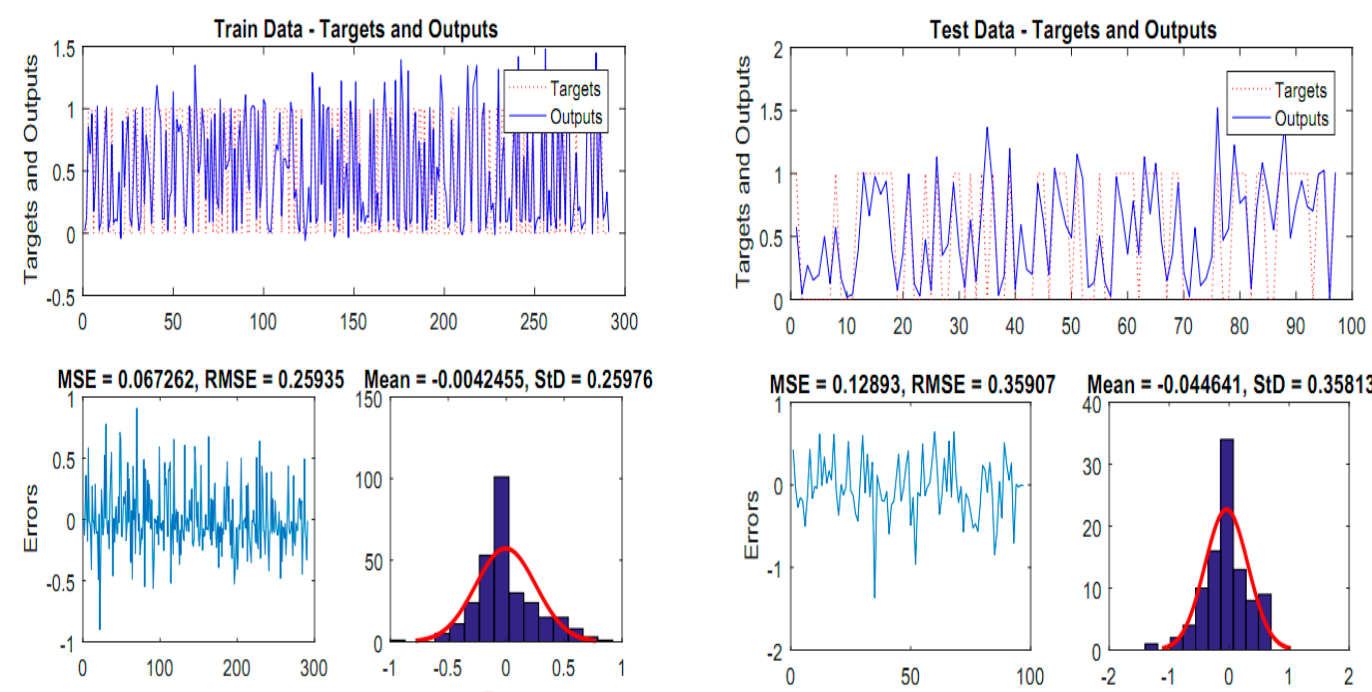

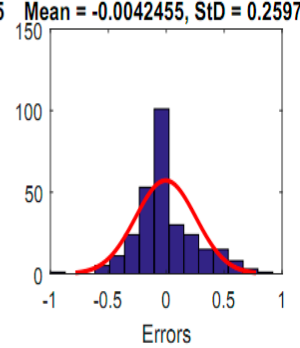

(c)

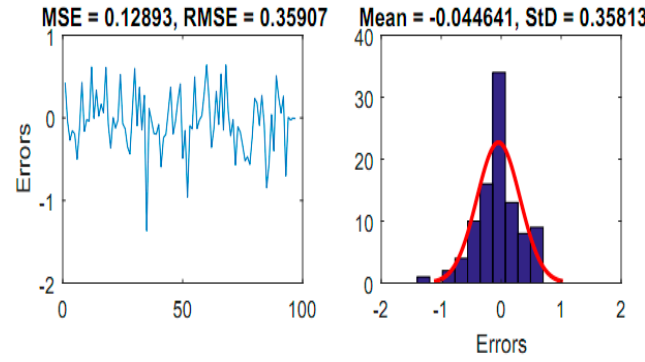

(d)

Figure 9. Cont. 

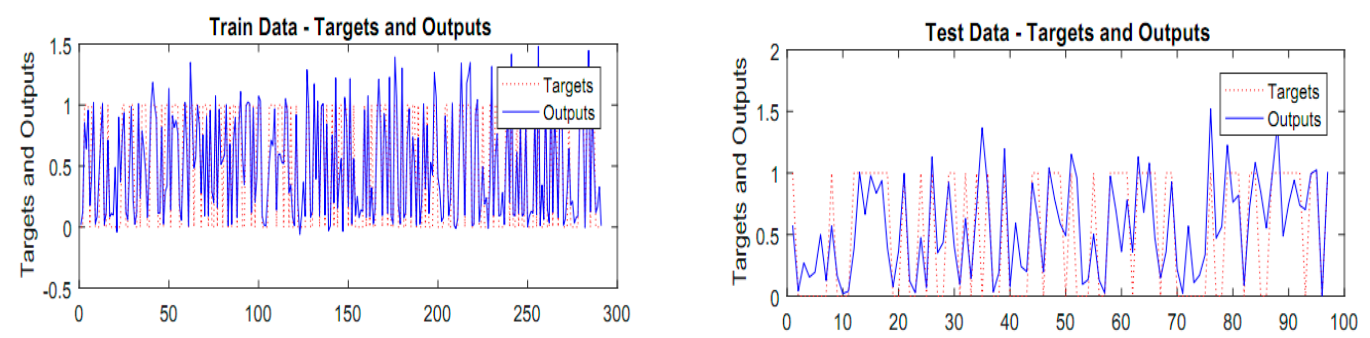

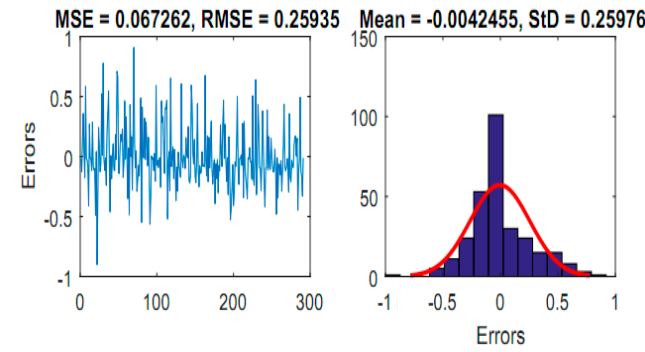

(e)
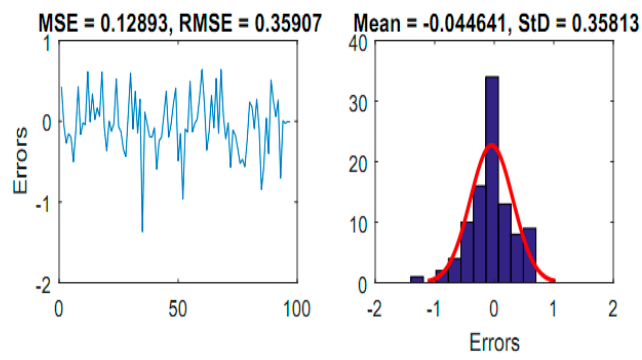

(f)

Figure 9. RMSE value of training of (a) ANFIS-CA, (c) ANFIS-BA, (e) ANFIS-IWO and for testing data samples (b) ANFIS-CA, (d) ANFIS-BA, and (f) ANFIS-IWO.

In addition, it should be noted that the processing speed of the models is also important nowadays. The processing time of 1000 iterations was then estimated as 1, 120, $260 \mathrm{~s}$ and $1100 \mathrm{~s}$ for the ANFIS-BA, ANFIS-CA, and ANFIS-IWO hybrid models by coding, respectively. As a result, the processing speed of ANFIS-CA had the least time, and the ANFIS-BA model had the highest process time. On the other hand, we examined the convergence of each model in the training phase (Figure 10).

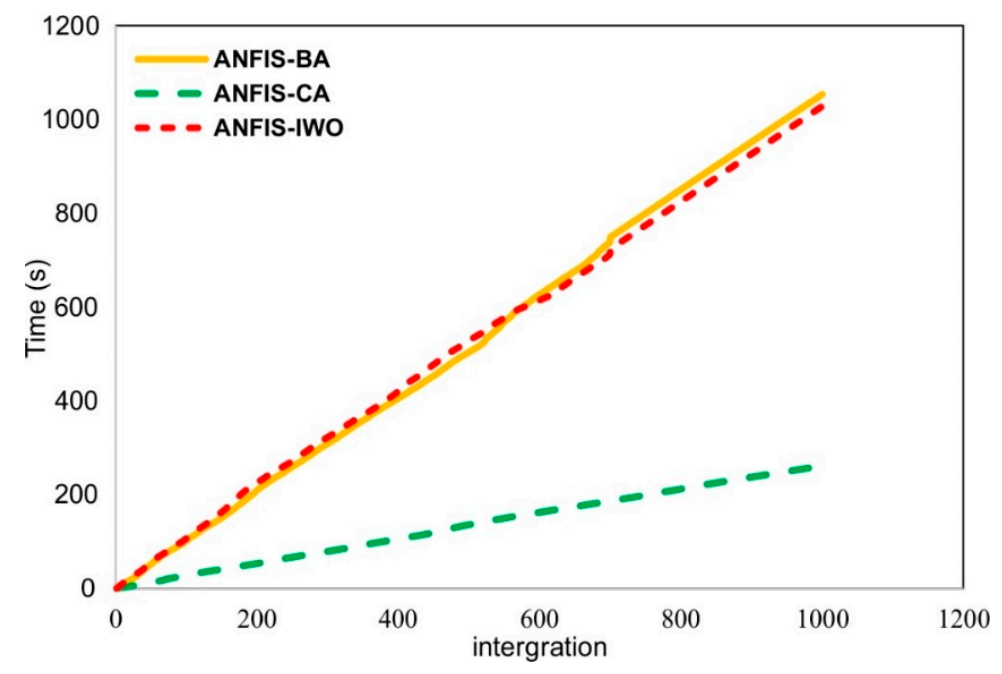

Figure 10. Cumulative curve of speed processing from applied models.

The convergence curve was gained by graphing the calculated function of cost in each iteration of three models (Figure 11). Results showed that cost-function values of the ANFIS-CA model were fixed in the 25th iteration, which indicates an iteration convergence of this model in comparison to other models. On the contrary, ANFIS-BA and ANFIS-IWO models converged in 450th and 625th iterations indicating the slow speed of these models in achieving convergence, respectively. 


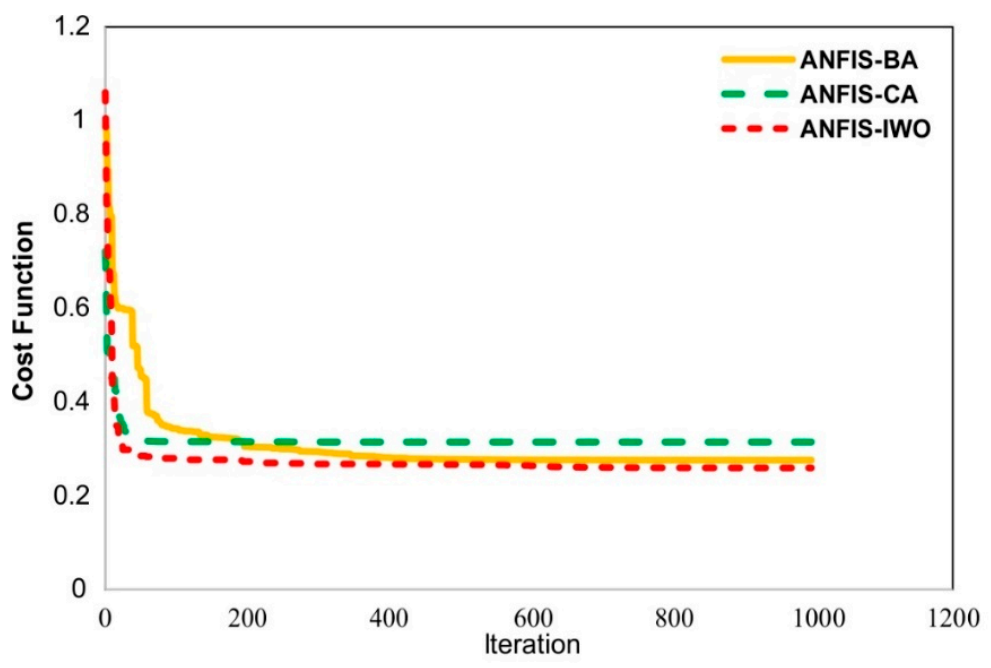

Figure 11. Speed of convergence of applied models.

\subsection{Model Configuration and Generating of FSMs Using ANFIS Ensemble Models}

As the main aim of flood susceptibility modeling was the reorganization of prone areas with higher probability of flooding; therefore, three optimization models-namely cultural, bees, and invasive weed optimization algorithms-were combined with SWARA-ANFIS to optimize the model for identifying flood prone areas with higher accuracy. ANFIS hybrid models were built using the training dataset and SWARA method values which were standardized between 0 and 1 in MATLAB R2016 software, The MathWorks, Inc, Massachusetts, MA, USA. Then, the constructed models were applied to the entire study area to create flood susceptibility probability (indices) and finally these indices for each pixel size (pixel-by-pixel) was used to create the final FSMs in ArcGIS 10.2 for the Haraz watershed. In the next step, indexes were reclassified into five classes (very low, low, moderate, high, and very high susceptibility) using the quantile method [18]. Three FSMs were then developed for comparative visualization, as shown in Figure 12a-c. Results demonstrated that the areas near rivers with lower slopes and altitudes had higher probabilities of flooding. 

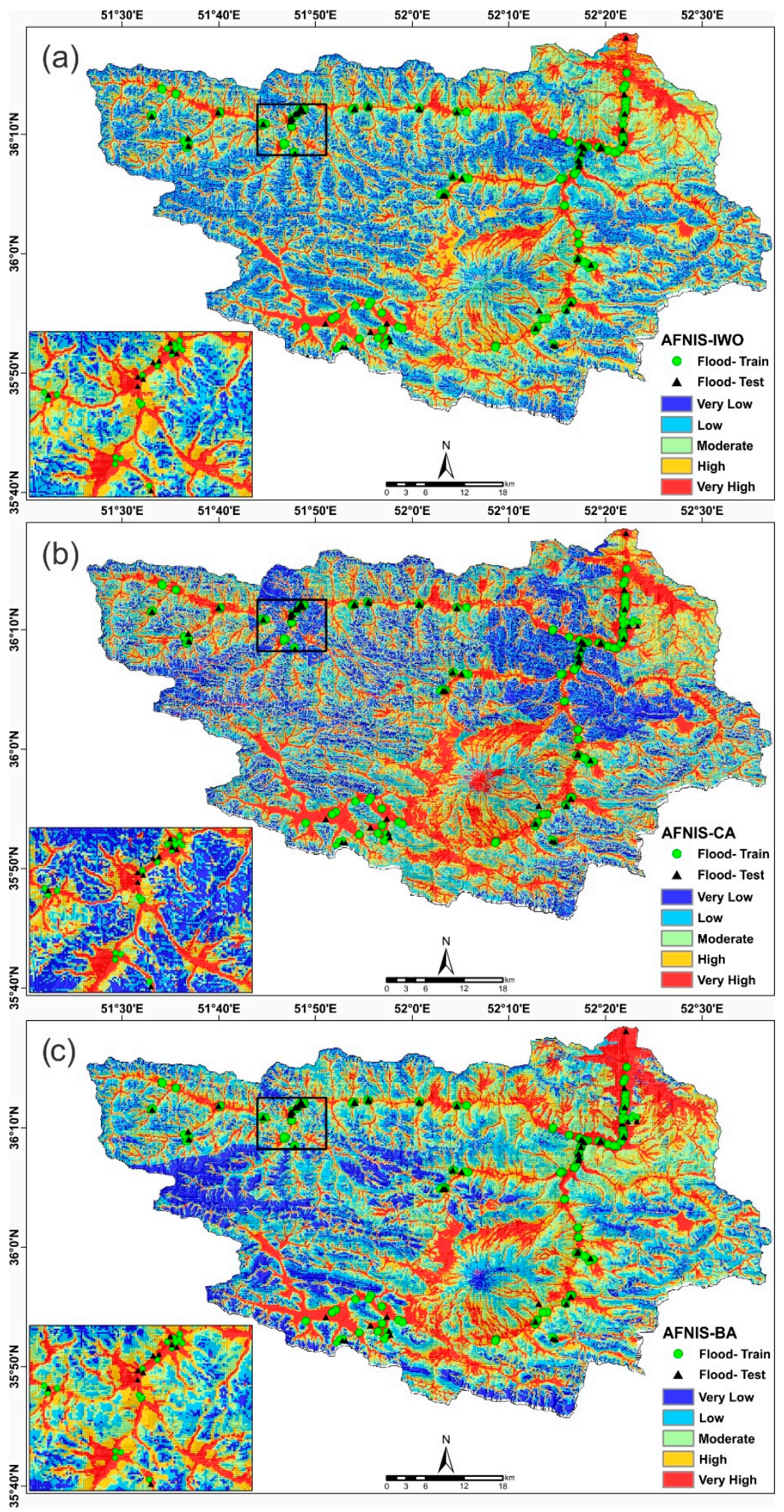

Figure 12. FSM using ANFIS-IWO (a), ANFIS-CA (b), and ANFIS-BA (c) for Haraz watershed.

\subsection{Validation of Flood Susceptibility Maps}

For validation of the three FSMs, both success and prediction rate curves were applied. The ROC plots are shown in Figure 13a,b. For the training phase, the ANFIS-IWO had the highest AUROC (0.948), followed by ANFIS-BA (0.946) and ANFIS-CA (0.942), implying that ANFIS-IWO had a 
fitter degree with training dataset. The validation of three obtained maps for the testing dataset revealed that ANFIS-BA (0.944) had a higher flood prediction capability for the Haraz watershed, followed by ANFIS-IWO (0.939) and ANFIS-CA (0.932). According to the relationship between AUROC and prediction capabilities of models, these models showed excellent performances based on the following classification: 0.5-0.6 (poor), 0.6-0.7 (average), 0.7-0.8 (good), 0.8-0.9 (very good), and $0.9-1$ (excellent) $[25,90]$.

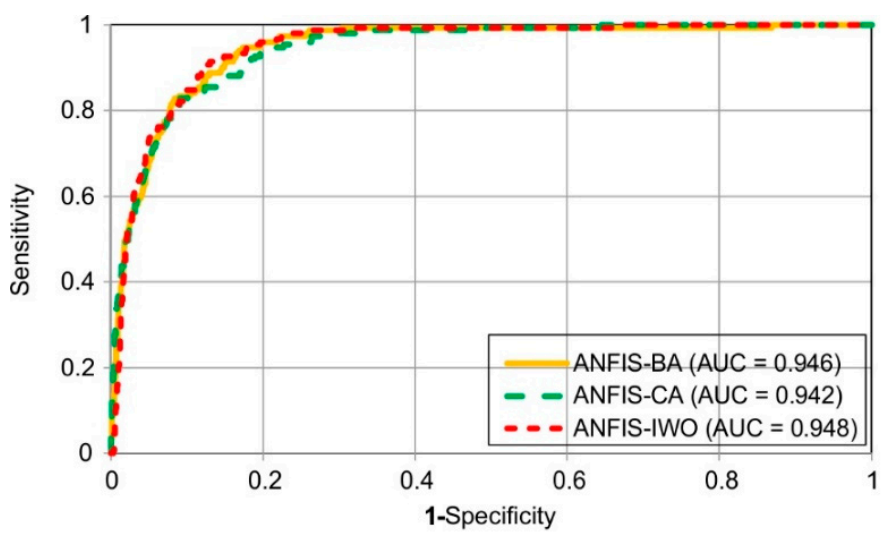

(a)

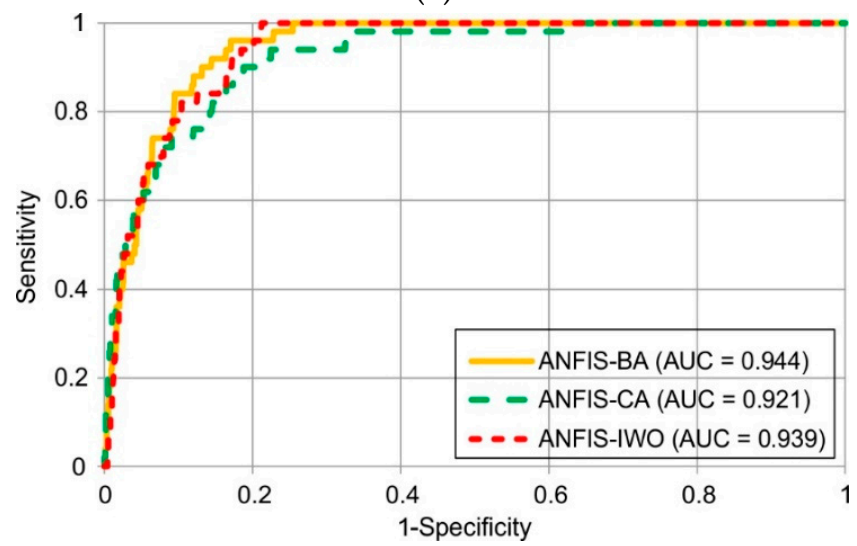

(b)

Figure 13. Model validation by success rate (a) and prediction rate (b) for three hybrid models.

As the most appropriate model to predict FSM for the Haraz watershed was the ANFIS-BA algorithm, the other two hybrid models had overestimated the results in very low, high, and very high susceptibility classes and underestimated in low and moderate classes (Figure 14). It can be seen that, according to the ANFIS-BA algorithm, the very high susceptibility class covered $17 \%$ of the study area, and analysis of flood location revealed that about $63 \%$ of total flood locations was located in this class. Overall, the very high and high classes contained about $85 \%$ of the total flood locations. The low and moderate classes covered about $50 \%$ of the study area according to the ANFIS-BA algorithm.

Results of the Freidman and Wilcoxon tests are shown in Tables 2 and 3. They revealed that since the $p$-value was less than $0.05(0.00)$ and chi-square was more than 3.84 (standard value), the null hypothesis was rejected, indicating there were significant differences among the three flood susceptibility models.

The Wilcoxon test was carried out to check the statistical significance of pairwise differences between flood models. Based on the judgment, there were significant differences between ANFIS-CA and ANFIS-BA and ANFIS-CA and ANFIS-IWO; however, there was no significant difference between ANFIS-BA and ANFIS-IWO algorithms. 


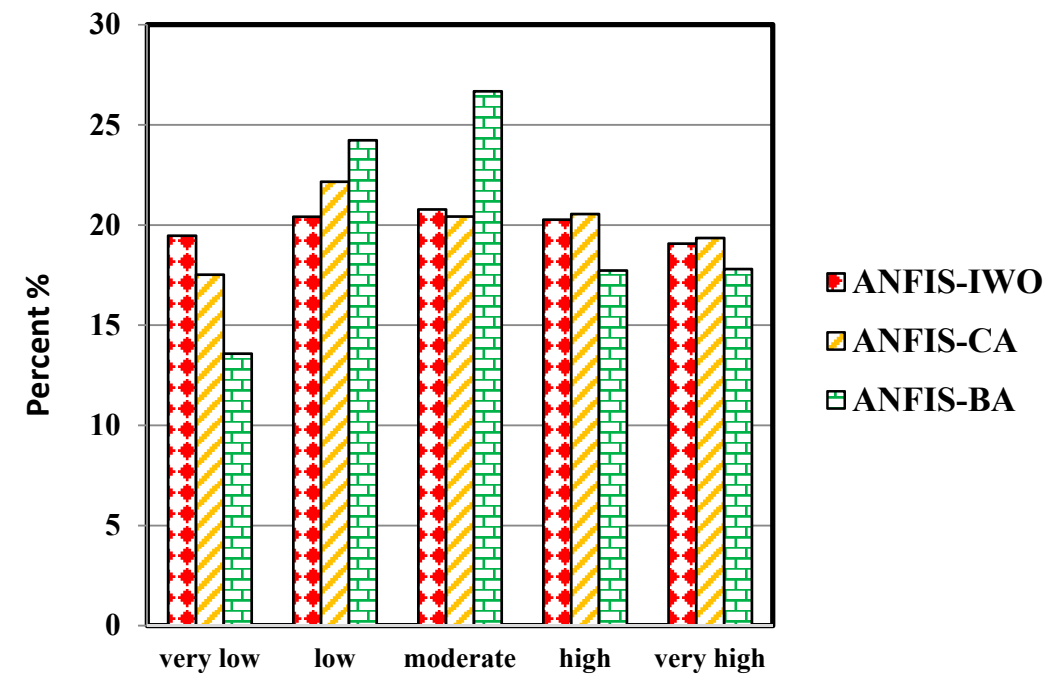

Figure 14. Percentages of different flood susceptibility classes in the Haraz watershed.

Table 2. Freidman test achievement

\begin{tabular}{ccccc}
\hline Number & Flood Models & Mean Ranks & Chi-Square & $p$-Value (Significance) \\
\hline 1 & ANFIS-CA & 1.68 & & \\
2 & ANFIS-BA & 2.08 & 16.6 & 0.00 \\
3 & ANFIS-IWO & 2.24 & & \\
\hline
\end{tabular}

Table 3. Results of Wilcoxon signed-rank test

\begin{tabular}{ccccc}
\hline Number & Pairwise Comparison & z-Score & $\boldsymbol{p}$-Value (Significance) & Judgment \\
\hline 1 & ANFIS-CA vs. ANFIS-BA & -3.225 & 0.001 & Yes \\
2 & ANFIS-CA vs. & -3.906 & 0.000 & Yes \\
3 & ANFIS-IWO & -1.128 & 0.259 & NO \\
\hline
\end{tabular}

\section{Discussion}

Flooding is known as the most frequent and destructive natural hazard. The occurrence of floods is increasing worldwide and its human losses and socio-economic damages pose huge pressure on communities. This trend is occurring in northern Iran as well, especially in the Haraz watershed. This huge burden of floods on human societies has brought about geophysicists, hydrologists, water resources engineers, geologists, and geomorphologists to study this phenomenon from different aspects such that its management can be met and its financial damages can be mitigated. One of the most important tasks of these scientists is to identify the areas within a watershed through different tools that are very vulnerable to flood generation. Field work might be preferable; however, it is costly, time-consuming, and hard to conduct. Therefore, a modeling approach is always an alternate tool to direct measurement of flood characteristics. The present study introduces three novel hybrid models-ANFIS-CA, ANFIS-BA, and ANFIS-IWO algorithms-for identifying flood prone areas of the Haraz watershed with a high precision and compares their prediction capabilities. In this study, the SWARA method was adopted to select the most effective factors and the most effective class of each of 10 conditioning factors. Our finding indicated that all factors had significant relationships with floods such that they were all selected for flood susceptibility modeling. Three flood susceptibility maps were generated using three above-mentioned novel hybrid models and they were then classified into five classes. 
A comparison between the results of modeling process and five flood susceptibility classes including very low, low, moderate, high, and very high susceptibility classless on the terrain was taken place. Basically, in the very high and high susceptibility classes, all hybrid models covered low lands (flats) and the areas around the rivers. Most of observation floods are occurred due to overbanking the flow. Also, the floodplains over the study area are surrounded by this class of susceptibility. This region located generally in the elevations less than $400 \mathrm{~m}$ above sea level, slope angle less than $8 \%$ in concave slopes with rainfall more than about $400 \mathrm{~mm}$ and the distance less than $200 \mathrm{~m}$ from the rivers. The obtained results of modeling process indicated that the ANFIS-CA and ANFIS-IWO have occupied more pixels of very high susceptibility class in comparison to ANFIS-BA algorithm.

In the low and moderate susceptibility class, with increasing the distance from the rivers, the areas where are covered by floods will be decreased. This region generally occupied by slope between $8 \%$ and $12 \%$, elevation above sea level between 400 and $2000 \mathrm{~m}$, concave and convex slopes, and the distance from the river between 200 and $700 \mathrm{~m}$. The results of modeling process concluded that the ANFIS-BA hybrid model has covered most areas of the study area in comparison to the ANFIS-CA and ANFIS-IWO hybrid models.

The very low susceptibility class mainly included the mountainous areas and hill slopes which are much far away from the rivers compared to the other susceptibility classes. In term of topography, this zone is usually located in the areas where the slope angle and elevation above-sea level are more than $20 \%$ and $2000 \mathrm{~m}$, respectively. The slope shape in this class is mainly concave and convex slopes and the distance from the river is more than $700 \mathrm{~m}$. The modelling process revealed that the ANFIS-BA hybrid model has the least areas over the study area unlike to the ANFIS-CA and ANFIS-IWO hybrid models.

Three ANFIS ensemble optimization approaches-including ANFIS-CA, ANFIS-BA and ANFIS-IWO-were designed to flood modeling of the Haraz watershed for which the entire dataset was divided into two series; $70 \%$ of the data for training of models and the rest for testing. Results of model evaluation using RMSE for the best degree of fit in the training phase and the best prediction accuracy in the testing phase revealed that the ANFIS-IWO optimization algorithm indicated a better performance in training and testing phases, followed by ANFIS-BA and ANFIS-CA, while all three models provided acceptable results for flood modeling. However, results of the AUC showed that ANFIS-IWO had the best degree of fit in the training phase which was coincident with the results of RMSE; whereas, in the testing phase, the results of AUC revealed that ANFIS-BA had the best prediction power than other models. The most important disadvantage of RMSE was that it acted based only on error assessments; therefore, better approaches must be found to resolve this weak spot, as the model should be chosen based on its abilities. Treating the ROC and AUC based on true positive (TP), true negative (TN), false positive (FP), and false negative (FN) showed more accurate evaluation of the models than RMSE [39]. According to AUC, the ANFIS-IWO had the fittest degree to the training data; however, the ANFIS-BA had the highest prediction capabilities compare other methods in testing phase. As the testing dataset was not used for modeling, the model evaluation must be performed based on the testing dataset. The challenge here is determining how it is possible for a model to show highest degree of fit in the training phase (ANFIS-IWO) but not to have the highest prediction power in the testing phase. Termeh et al. [39] stated that this situation can take place in the models with the over fitting problem. The BA algorithm used a series of parameters including number of scout bees, best patches, as well as elite patches in the selected patches, amount of employed bees in the elite patches, number of recruited bees in the non-elite best patches, the neighborhood size for each patch, number of iterations, together with difference between first and last iterations value; make it robust. The bees algorithm has local and global searching capabilities that find the best locations. Finally, three designed models were also evaluated for processing speed and convergence criterion. Results indicated that although ANFIS-CA had the lowest prediction power than other models but acquired the lowest processing speed and the highest speed of convergence. 
Some studies focused on spatial prediction of floods using machine learning and optimization algorithms over the world. In this case, Chapi et al. [38] introduced a new machine learning algorithm, namely bagging-logistic model tree (BA-LMT) for flood modelling. They concluded that the proposed ensemble model had outperformed the LMT, the logistic regression, the Bayesian logistic regression, and the random forest algorithms. Khosravi et al. [36] compared some soft computing benchmark machine learning algorithms - such as logistic model trees (LMT), reduced error pruning trees (REPT), naïve Bayes trees (NBT), and alternating decision trees (ADT)—for flash flood susceptibility mapping. They revealed that the ADT model had the highest prediction capability, followed by the NBT, LMT, and REPT algorithms, respectively. The results of above mentioned studies indicated the capability of machine learning algorithms in spatial prediction of floods. However, there are some other studies which conducted on optimization as evolutionary algorithms for flood susceptibility assessment such as Bui et al. [25], Hong et al. [24], Ahmadlou et al. [70] and Termeh et al. [39]. Among these studies, Bui et al. [25] introduced a new hybrid model of neural fuzzy inference system and metaheuristic optimization including evolutionary genetic and particle swarm optimization (MONF) for flood mapping. The obtained results were confirmed and compared with the J48 decision tree, the random forest, the multi-layer perceptron neural network, the support vector machine, and the adaptive neuro fuzzy inference system (ANFIS) algorithms. Additionally, Hong et al. [24] concluded that the new hybrid optimization algorithm of ANFIS-differential evolution (ANFIS-DE) outperformed and outclassed of the ANFIS-genetic algorithm (ANFIS-GA). Also, the results of Termeh et al. [39] indicated the highest capability of ANFIS-PSO ensemble model in comparison to ANFIS-DE and ANFIS-GA models. The mentioned studies indicated that the optimization algorithms for flood modeling in the different study areas over the world had more power prediction in comparison to machine learning algorithms. Basically, the results of this study which illustrated the ability of new optimization algorithm—namely bees—for flood susceptibility assessment in the study area are in agreement with other mentioned studies over the world. The bees algorithm is a more robust optimization algorithm in comparison to the CA and IWO algorithms in the study area.

What is pointed out from the above-mentioned studies is that each model has its own advantages and disadvantages. Thus, the new models must be applied and the model with the highest prediction power selected for further and future decisions. Moreover, it is better to state that some of machine learning models have weaknesses; thus, new hybrid models should be continuously introduced to resolve this problem [32]. The current research like other studies has some uncertainties especially in (1) variable factors, such as rainfall, land-use; (2) impact of climate change on flood occurrences; (3) impact of human activities on flood occurrences; and (4) determination of flood inundation map along with flood susceptibility maps. Thus, for future cases, it is recommended that 2-D flood inundation maps of flood-prone areas achieved by the current research should be produced using some commonly hydraulic models such as Hydrologic Engineering Center-River Analysis System (HEC-RAS) software.

\section{Conclusions}

FSM especially in ungauged watersheds has a scientific and practical value in the context of basin-scale water resources management and is a base for hazard and risk mapping. It can be considered as a useful tool for land-use planning, decision making, and flood disaster management. Due to complexity and non-linearity structure of watersheds, floods cannot be modeled by employing classic statistical and physically-based distributed methods; therefore, for the determination of flood prone areas in the Haraz watershed, Iran, with high accuracy, new hybrid artificial intelligence models were used. To fulfill this purpose, 201 flood locations were collected and randomly divided into two groups for training and validation dataset, and 10 flood conditioning factors were then selected. ANFIS weighted by SWARA method was applied to make an initial flood susceptibility model and three optimization models—namely CA, BA, and IWO-were adopted to optimize the models. These optimization techniques find optimal parameters and also decrease the problems of local minimum and are therefore appropriate for the training of artificial intelligence methods and 
optimizing their results as well, especially for solving complex problems such as flood prediction. It is obvious that more precise flood susceptibility maps can decrease the cost and damages from flooding. Finally, FSMs were constructed using ANFIS-CA, ANFIS-BA, and ANFIS-IWO and then classified into five categories using the quantile method in order to produce the susceptibility maps and the results of the achieved map represented very low, low, moderate, high, and very high susceptibility areas. Finally, these three new hybrid optimization models were evaluated using ROC and AUROC. Results revealed that ANFIS-IWO algorithm had a better degree of fit with the training dataset but ANFIS-BA had a higher prediction capability in FSM using the testing dataset followed by ANFIS-IWO and ANFIS-CA.

Author Contributions: D.T.B., K.K., S.L., H.S., M.P., V.P.S., K.C., A.S., S.P., W.C. and B.B.A contributed equally to the work. K.K. and M.P collected field data and conducted the flood mapping and analysis. K.K., H.S., M.P., K.C., A.S. and S.P wrote the manuscript. D.T.B., S.L., V.P.S., W.C. and B.B.A provided critical comments in planning this paper and edited the manuscript. All the authors discussed the results and edited the manuscript.

Funding: This research was financial supported by International Partnership Program of Chinese Academy of Sciences (grant no. 115242KYSB20170022), Iran National Science Foundation (INSF) through the research project no. 96004000, and Universiti Teknologi Malaysia (UTM) based on the Research University Grant (Q.J130000.2527.17H84).

Acknowledgments: We express our thanks to Editor-in-Chief of the Water journal and our two anonymous reviewers. With their comments and suggestions, we were able to significantly improve the quality of our paper.

Conflicts of Interest: No potential conflict of interest was reported by the authors.

\section{References}

1. Elkhrachy, I. Flash flood hazard mapping using satellite images and GIS tools: A case study of Najran City, Kingdom of Saudi Arabia (KSA). Egypt. J. Remote Sens. Space. Sci. 2015, 18, 261-278. [CrossRef]

2. Tehrany, M.S.; Pradhan, B.; Jebur, M.N. Flood susceptibility analysis and its verification using a novel ensemble support vector machine and frequency ratio method. Stoch. Environ. Res. Risk Assess. 2015, 29, 1149-1165. [CrossRef]

3. Youssef, A.M.; Pradhan, B.; Hassan, A.M. Flash flood risk estimation along the St. Katherine road, southern Sinai, Egypt using GIS based morphometry and satellite imagery. Environ. Earth Sci. 2011, 62, 611-623. [CrossRef]

4. Lee, E.H.; Kim, J.H.; Choo, Y.M.; Jo, D.J. Application of flood nomograph for flood forecasting in urban areas. Water 2018, 10, 53. [CrossRef]

5. Sarhadi, A.; Soltani, S.; Modarres, R. Probabilistic flood inundation mapping of ungauged rivers: Linking GIS techniques and frequency analysis. J. Hydrol. 2012, 458, 68-86. [CrossRef]

6. Luu, C.; von Meding, J. A flood risk assessment of quang nam, vietnam using spatial multicriteria decision analysis. Water 2018, 10, 461. [CrossRef]

7. Dutta, D.; Herath, S. Trend of Floods in Asia and Flood Risk Management with Integrated River Basin Approach. In Proceedings of the 2nd APHW Conference, Singapore, 5-8 July 2004; pp. 55-63.

8. Smith, K. Environmental Hazards: Assessing Risk and Reducing Disaster; Routledge: London, UK, 2013.

9. Khosravi, K.; Nohani, E.; Maroufinia, E.; Pourghasemi, H.R. A GIS-based flood susceptibility assessment and its mapping in iran: A comparison between frequency ratio and weights-of-evidence bivariate statistical models with multi-criteria decision-making technique. Nat. Hazards 2016, 83, 947-987. [CrossRef]

10. Khosravi, K.; Pourghasemi, H.R.; Chapi, K.; Bahri, M. Flash flood susceptibility analysis and its mapping using different bivariate models in Iran: A comparison between Shannon's entropy, statistical index, and weighting factor models. Environ. Monit. Assess. 2016, 188, 656. [CrossRef] [PubMed]

11. Shafizadeh-Moghadam, H.; Valavi, R.; Shahabi, H.; Chapi, K.; Shirzadi, A. Novel forecasting approaches using combination of machine learning and statistical models for flood susceptibility mapping. J. Environ. Manag. 2018, 217, 1-11. [CrossRef] [PubMed]

12. Chapi, K. Monitoring and Modeling of Runoff Generating Areas in a Small Agricultural Watershed. Ph.D. Thesis, University of Guelph, Guelph, Canada, 2010. 
13. Chapi, K.; Rudra, R.P.; Ahmed, S.I.; Khan, A.A.; Gharabaghi, B.; Dickinson, W.T.; Goel, P.K. Spatial-temporal dynamics of runoff generation areas in a small agricultural watershed in southern Ontario. J. Water Resour. Prot. 2015, 7, 14-40. [CrossRef]

14. Fenicia, F.; Kavetski, D.; Savenije, H.H.; Clark, M.P.; Schoups, G.; Pfister, L.; Freer, J. Catchment properties, function, and conceptual model representation: Is there a correspondence? Hydrol. Process. 2014, 28, 2451-2467. [CrossRef]

15. Kisi, O.; Nia, A.M.; Gosheh, M.G.; Tajabadi, M.R.J.; Ahmadi, A. Intermittent streamflow forecasting by using several data driven techniques. Water Resour. Manag. 2012, 26, 457-474. [CrossRef]

16. Ganguli, P.; Reddy, M.J. Probabilistic assessment of flood risks using trivariate copulas. Theor. Appl. Climatol. 2013, 111, 341-360. [CrossRef]

17. Refsgaard, J.C. Parameterisation, calibration and validation of distributed hydrological models. J. Hydrol. 1997, 198, 69-97. [CrossRef]

18. Cea, L.; Bladé, E. A simple and efficient unstructured finite volume scheme for solving the shallow water equations in overland flow applications. Water Resour. Res. 2015, 51, 5464-5486. [CrossRef]

19. Costabile, P.; Costanzo, C.; Macchione, F. A storm event watershed model for surface runoff based on 2D fully dynamic wave equations. Hydrol. Process. 2013, 27, 554-569. [CrossRef]

20. Xia, X.; Liang, Q.; Ming, X.; Hou, J. An efficient and stable hydrodynamic model with novel source term discretization schemes for overland flow and flood simulations. Water Resour. Res. 2017, 53, 3730-3759. [CrossRef]

21. Bellos, V.; Tsakiris, G. A hybrid method for flood simulation in small catchments combining hydrodynamic and hydrological techniques. J. Hydrol. 2016, 540, 331-339. [CrossRef]

22. Liang, D.; Özgen, I.; Hinkelmann, R.; Xiao, Y.; Chen, J.M. Shallow water simulation of overland flows in idealised catchments. Environ. Earth Sci. 2015, 74, 7307-7318. [CrossRef]

23. Singh, J.; Altinakar, M.S.; Ding, Y. Numerical modeling of rainfall-generated overland flow using nonlinear shallow-water equations. J. Hydrol. Eng. 2014, 20. [CrossRef]

24. Rahmati, O.; Naghibi, S.A.; Shahabi, H.; Bui, D.T.; Pradhan, B.; Azareh, A.; Rafiei-Sardooi, E.; Samani, A.N.; Melesse, A.M. Groundwater spring potential modelling: comprising the capability and robustness of three different modeling approaches. J. Hydrol. 2018, 565, 248-261. [CrossRef]

25. Bui, D.T.; Pradhan, B.; Nampak, H.; Bui, Q.-T.; Tran, Q.-A.; Nguyen, Q.-P. Hybrid artificial intelligence approach based on neural fuzzy inference model and metaheuristic optimization for flood susceptibilitgy modeling in a high-frequency tropical cyclone area using GIS. J. Hydrol. 2016, 540, 317-330.

26. Tyrna, B.; Assmann, A.; Fritsch, K.; Johann, G. Large-scale high-resolution pluvial flood hazard mapping using the raster-based hydrodynamic two-dimensional model flood FloodAreaHPC. J. Flood Risk Manag. 2018, 11, S1024-S1037. [CrossRef]

27. Al-Abadi, A.M.; Shahid, S.; Al-Ali, A.K. A GIS-based integration of catastrophe theory and analytical hierarchy process for mapping flood susceptibility: A case study of teeb area, southern Iraq. Environ. Earth Sci. 2016, 75, 1-19. [CrossRef]

28. Tehrany, M.S.; Pradhan, B.; Jebur, M.N. Flood susceptibility mapping using a novel ensemble weights-of-evidence and support vector machine models in GIS. J. Hydrol. 2014, 512, 332-343. [CrossRef]

29. Tehrany, M.S.; Pradhan, B.; Mansor, S.; Ahmad, N. Flood susceptibility assessment using GIS-based support vector machine model with different kernel types. Catena. 2015, 125, 91-101. [CrossRef]

30. Youssef, A.M.; Pradhan, B.; Sefry, S.A. Flash flood susceptibility assessment in Jeddah city (Kingdom of Saudi Arabia) using bivariate and multivariate statistical models. Environ. Earth Sci. 2016, 75, 12. [CrossRef]

31. Fotopoulos, F.; Makropoulos, C.; Mimikou, M.A. Validation of satellite rainfall products for operational flood forecasting: The case of the Evros catchment. Theor. Appl. Climatol. 2011, 104, 403-414. [CrossRef]

32. Tehrany, M.S.; Pradhan, B.; Jebur, M.N. Spatial prediction of flood susceptible areas using rule based decision tree (DT) and a novel ensemble bivariate and multivariate statistical models in GIS. J. Hydrol. 2013, 504, 69-79. [CrossRef]

33. Pradhan, B. Flood susceptible mapping and risk area delineation using logistic regression, GIS and remote sensing. J. Spatial Hydrol. 2010, 9, 1-18.

34. Gigović, L.; Pamučar, D.; Bajić, Z.; Drobnjak, S. Application of GIS-interval rough AHP methodology for flood hazard mapping in urban areas. Water 2017, 9, 360. [CrossRef] 
35. Kia, M.B.; Pirasteh, S.; Pradhan, B.; Mahmud, A.R.; Sulaiman, W.N.A.; Moradi, A. An artificial neural network model for flood simulation using GIS: Johor River Basin, Malaysia. Environ. Earth Sci. 2012, 67, 251-264. [CrossRef]

36. Khosravi, K.; Pham, B.T.; Chapi, K.; Shirzadi, A.; Shahabi, H.; Revhaug, I.; Prakash, I.; Bui, D.T. A comparative assessment of decision trees algorithms for flash flood susceptibility modeling at Haraz watershed, northern Iran. Sci. Total Environ. 2018, 627, 744-755. [CrossRef] [PubMed]

37. Hong, H.; Panahi, M.; Shirzadi, A.; Ma, T.; Liu, J.; Zhu, A.-X.; Chen, W.; Kougias, I.; Kazakis, N. Flood susceptibility assessment in Hengfeng area coupling adaptive neuro-fuzzy inference system with genetic algorithm and differential evolution. Sci. Total Environ. 2017, 621, 1124-1141. [CrossRef] [PubMed]

38. Chapi, K.; Singh, V.P.; Shirzadi, A.; Shahabi, H.; Bui, D.T.; Pham, B.T.; Khosravi, K. A novel hybrid artificial intelligence approach for flood susceptibility assessment. Environ. Model. Softw. 2017, 95, 229-245. [CrossRef]

39. Termeh, S.V.R.; Kornejady, A.; Pourghasemi, H.R.; Keesstra, S. Flood susceptibility mapping using novel ensembles of adaptive neuro fuzzy inference system and metaheuristic algorithms. Sci. Total Environ. 2018, 615, 438-451. [CrossRef] [PubMed]

40. Maier, H.R.; Jain, A.; Dandy, G.C.; Sudheer, K.P. Methods used for the development of neural networks for the prediction of water resource variables in river systems: Current status and future directions. Environ. Model. Softw. 2010, 25, 891-909. [CrossRef]

41. Dottori, F.; Martina, M.L.V.; Figueiredo, R. A methodology for flood susceptibility and vulnerability analysis in complex flood scenarios. J. Flood Risk Manag. 2018, 11, S632-S645. [CrossRef]

42. Ghalkhani, H.; Golian, S.; Saghafian, B.; Farokhnia, A.; Shamseldin, A. Application of surrogate artificial intelligent models for real-time flood routing. Water Environ. J. 2013, 27, 535-548. [CrossRef]

43. Rezaeianzadeh, M.; Tabari, H.; Yazdi, A.A.; Isik, S.; Kalin, L. Flood flow forecasting using ANN, ANFIS and regression models. Neural Comput. Appl. 2014, 25, 25-37. [CrossRef]

44. Chang, F.-J.; Tsai, M.-J. A nonlinear spatio-temporal lumping of radar rainfall for modeling multi-step-ahead inflow forecasts by data-driven techniques. J. Hydrol. 2016, 535, 256-269. [CrossRef]

45. Güçlü, Y.S.; Şen, Z. Hydrograph estimation with fuzzy chain model. J. Hydrol. 2016, 538, 587-597. [CrossRef]

46. Lohani, A.; Kumar, R.; Singh, R. Hydrological time series modeling: A comparison between adaptive neuro-fuzzy, neural network and autoregressive techniques. J. Hydrol. 2012, 442, 23-35. [CrossRef]

47. Shu, C.; Ouarda, T. Regional flood frequency analysis at ungauged sites using the adaptive neuro-fuzzy inference system. J. Hydrol. 2008, 349, 31-43. [CrossRef]

48. Mukerji, A.; Chatterjee, C.; Raghuwanshi, N.S. Flood forecasting using ANN, Neuro-Fuzzy, and Neuro-GA models. J. Hydrol. Eng. 2009, 14, 647-652. [CrossRef]

49. Nayak, P.C.; Sudheer, K.P.; Rangan, D.M.; Ramasastri, K.S. Short-term flood forecasting with a neurofuzzy model. Water Resour. Res. 2005, 41. [CrossRef]

50. Pham, B.T.; Bui, D.T.; Dholakia, M.; Prakash, I.; Pham, H.V. A comparative study of least square support vector machines and multiclass alternating decision trees for spatial prediction of rainfall-induced landslides in a tropical cyclones area. Geotech. Geol. Eng. 2016, 34, 1807-1824. [CrossRef]

51. Tien Bui, D.; Pradhan, B.; Lofman, O.; Revhaug, I. Landslide susceptibility assessment in vietnam using support vector machines, decision tree, and Naive Bayes Models. Math. Probl. Eng. 2012, 2012, 974638. [CrossRef]

52. Guzzetti, F.; Mondini, A.C.; Cardinali, M.; Fiorucci, F.; Santangelo, M.; Chang, K.-T. Landslide inventory maps: New tools for an old problem. Earth Sci. Rev. 2012, 112, 42-66. [CrossRef]

53. Pham, B.T.; Pradhan, B.; Bui, D.T.; Prakash, I.; Dholakia, M. A comparative study of different machine learning methods for landslide susceptibility assessment: A case study of Uttarakhand area (India). Environ. Model. Softw. 2016, 84, 240-250. [CrossRef]

54. Akgun, A. A comparison of landslide susceptibility maps produced by logistic regression, multi-criteria decision, and likelihood ratio methods: A case study at İzmir, turkey. Landslides 2012, 9, 93-106. [CrossRef]

55. Cook, A.; Merwade, V. Effect of topographic data, geometric configuration and modeling approach on flood inundation mapping. J. Hydrol. 2009, 377, 131-142. [CrossRef]

56. Moore, I.D.; Grayson, R.B. Terrain-based catchment partitioning and runoff prediction using vector elevation data. Water Resour. Res. 1991, 27, 1177-1191. [CrossRef]

57. Kirkby, M.; Beven, K. A physically based, variable contributing area model of basin hydrology. Hydrol. Sci. J. $1979,24,43-69$. 
58. Beven, K.; Kirkby, M.; Schofield, N.; Tagg, A. Testing a physically-based flood forecasting model (topmodel) for three UK catchments. J. Hydrol. 1984, 69, 119-143. [CrossRef]

59. Glenn, E.P.; Morino, K.; Nagler, P.L.; Murray, R.S.; Pearlstein, S.; Hultine, K.R. Roles of saltcedar (Tamarix spp.) and capillary rise in salinizing a non-flooding terrace on a flow-regulated desert river. J. Arid Environ. 2012, 79, 56-65. [CrossRef]

60. Chung, C.-J.F.; Fabbri, A.G. Validation of spatial prediction models for landslide hazard mapping. Nat. Hazards 2003, 30, 451-472. [CrossRef]

61. Keršuliene, V.; Zavadskas, E.K.; Turskis, Z. Selection of rational dispute resolution method by applying new step-wise weight assessment ratio analysis (SWARA). J. Bus. Econ. Manag. 2010, 11, 243-258. [CrossRef]

62. Keršulienè, V.; Turskis, Z. Integrated fuzzy multiple criteria decision making model for architect selection. Technol. Econ. Dev. Econ. 2011, 17, 645-666. [CrossRef]

63. Zolfani, S.H.; Aghdaie, M.H.; Derakhti, A.; Zavadskas, E.K.; Varzandeh, M.H.M. Decision making on business issues with foresight perspective; an application of new hybrid MCDM model in shopping mall locating. Expert Syst. Appl. 2013, 40, 7111-7121. [CrossRef]

64. Takagi, T.; Sugeno, M. Fuzzy identification of systems and its applications to modeling and control. IEEE Trans. Syst. Man Cybern. 1985, SMC-15, 116-132. [CrossRef]

65. Jang, J.-S.R. ANFIS: Adaptive-network-based fuzzy inference system. IEEE Trans. Syst. Man Cybern. 1993, 23, 665-685. [CrossRef]

66. Phootrakornchai, W.; Jiriwibhakorn, S. Online critical clearing time estimation using an adaptive neuro-fuzzy inference system (ANFIS). Int. J. Electr. Power Energy Syst. 2015, 73, 170-181. [CrossRef]

67. Rezakazemi, M.; Dashti, A.; Asghari, M.; Shirazian, S. $\mathrm{H}_{2}$-selective mixed matrix membranes modeling using ANFIS, PSO-ANFIS, GA-ANFIS. Int. J. Hydrogen Energy 2017, 42, 15211-15225. [CrossRef]

68. Jang, J.-S.; Sun, C.-T. Neuro-fuzzy modeling and control. Proc. IEEE 1995, 83, 378-406. [CrossRef]

69. Chen, W.; Panahi, M.; Pourghasemi, H.R. Performance evaluation of GIS-based new ensemble data mining techniques of adaptive neuro-fuzzy inference system (ANFIS) with genetic algorithm (GA), differential evolution (DE), and particle swarm optimization (PSO) for landslide spatial modelling. Catena 2017, 157, 310-324. [CrossRef]

70. Ahmadlou, M.; Karimi, M.; Alizadeh, S.; Shirzadi, A.; Parvinnejhad, D.; Shahabi, H.; Panahi, M. Flood susceptibility assessment using integration of adaptive network-based fuzzy inference system (ANFIS) and biogeography-based optimization (BBO) and BAT algorithms (BA). Geocarto Int. 2018, 1-21. [CrossRef]

71. Reynolds, R.G. An introduction to cultural algorithms. In Proceedings of the Third Annual Conference on Evolutionary Programming, Singapore, 24 February 1994.

72. Reynolds, R.G. Cultural Algorithms: Theory and Applications; McGraw-Hill Ltd.: Maidenhead, UK, 1999; pp. 367-378.

73. Reynolds, R.G.; Ali, M.; Jayyousi, T. Mining the social fabric of archaic urban centers with cultural algorithms. Computer 2008, 41, 64-72. [CrossRef]

74. Soza, C.; Becerra, R.L.; Riff, M.C.; Coello, C.A.C. Solving timetabling problems using a cultural algorithm. Appl. Soft Comput. 2011, 11, 337-344. [CrossRef]

75. Pham, D.; Ghanbarzadeh, A.; Koc, E.; Otri, S.; Rahim, S.; Zaidi, M. The Bees Algorithm. Technical Note; Manufacturing Engineering Centre, Cardiff University: Wales, UK, 2005; pp. 1-57.

76. Pham, D.; Ghanbarzadeh, A.; Koc, E.; Otri, S.; Rahim, S.; Zaidi, M. The bees algorithm-A novel tool for complex optimisation. Intell. Prod. Mach. Syst. 2006, 454-459. [CrossRef]

77. Mehrabian, A.R.; Lucas, C. A novel numerical optimization algorithm inspired from weed colonization. Ecol. Inf. 2006, 1, 355-366. [CrossRef]

78. Ghasemi, M.; Ghavidel, S.; Akbari, E.; Vahed, A.A. Solving non-linear, non-smooth and non-convex optimal power flow problems using chaotic invasive weed optimization algorithms based on chaos. Energy 2014, 73, 340-353. [CrossRef]

79. Naidu, Y.R.; Ojha, A. A hybrid version of invasive weed optimization with quadratic approximation. Soft Comput. 2015, 19, 3581-3598. [CrossRef]

80. Zhou, Y.; Luo, Q.; Chen, H.; He, A.; Wu, J. A discrete invasive weed optimization algorithm for solving traveling salesman problem. Neurocomputing 2015, 151, 1227-1236. [CrossRef]

81. Saravanan, B.; Vasudevan, E.R.; Kothari, D.P. A solution to unit commitment problem using invasive weed optimization algorithm. Front. Energy 2013, 7, 487-494. [CrossRef] 
82. Chen, W.; Peng, J.; Hong, H.; Shahabi, H.; Pradhan, B.; Liu, J.; Zhu, A.-X.; Pei, X.; Duan, Z. Landslide susceptibility modelling using GIS-based machine learning techniques for Chongren County, Jiangxi Province, China. Sci. Total Environ. 2018, 626, 1121-1135. [CrossRef] [PubMed]

83. Shahabi, H.; Hashim, M.; Ahmad, B.B. Remote sensing and GIS-based landslide susceptibility mapping using frequency ratio, logistic regression, and fuzzy logic methods at the central Zab basin, Iran. Environ. Earth Sci. 2015, 73, 8647-8668. [CrossRef]

84. Shirzadi, A.; Bui, D.T.; Pham, B.T.; Solaimani, K.; Chapi, K.; Kavian, A.; Shahabi, H.; Revhaug, I. Shallow landslide susceptibility assessment using a novel hybrid intelligence approach. Environ. Earth Sci. 2017, 76, 60. [CrossRef]

85. Shahabi, H.; Hashim, M. Landslide susceptibility mapping using GIS-based statistical models and remote sensing data in tropical environment. Sci. Rep. 2015, 5. [CrossRef] [PubMed]

86. Lee, S. Comparison of landslide susceptibility maps generated through multiple logistic regression for three test areas in korea. Earth Surf. Process. Landf. J. Br. Geomorphol. Res. Group 2007, 32, 2133-2148. [CrossRef]

87. Pradhan, B. A comparative study on the predictive ability of the decision tree, support vector machine and neuro-fuzzy models in landslide susceptibility mapping using GIS. Comput. Geosci. 2013, 51, 350-365. [CrossRef]

88. Friedman, M. The use of ranks to avoid the assumption of normality implicit in the analysis of variance. J. Am. Stat. Assoc. 1937, 32, 675-701. [CrossRef]

89. Beasley, T.M.; Zumbo, B.D. Comparison of aligned friedman rank and parametric methods for testing interactions in split-plot designs. Comput. Stat. Data Anal. 2003, 42, 569-593. [CrossRef]

90. Kantardzic, M. Data Mining: Concepts, Models, Methods, and Algorithms; John Wiley \& Sons Inc.: Hoboken, NJ, USA, 2011.

(C) 2018 by the authors. Licensee MDPI, Basel, Switzerland. This article is an open access article distributed under the terms and conditions of the Creative Commons Attribution (CC BY) license (http://creativecommons.org/licenses/by/4.0/). 